Canadian

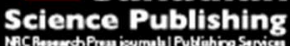

Applied Physiology, Nutrition, and Metabolism Physiologie appliquée, nutrition et métabolisme

\title{
Age, human performance and physical employment standards
}

\begin{tabular}{|r|l|}
\hline Journal: & Applied Physiology, Nutrition, and Metabolism \\
\hline Manuscript ID & apnm-2015-0483.R1 \\
\hline Manuscript Type: & Review \\
\hline Date Submitted by the Author: & $22-$ Nov-2015 \\
\hline Complete List of Authors: & $\begin{array}{l}\text { Kenny, Glen; University of Ottawa, } \\
\text { Groeller, Herbert; University of Wollongong, School of Medicine } \\
\text { McGinn, Ryan; University of Ottawa } \\
\text { Flouris, Andreas; University of Thessaly, Department of Exercise Science }\end{array}$ \\
\hline Keyword: & aging, worker, work ability, functional capacity, workplace interventions \\
\hline & \multicolumn{2}{l}{} \\
\hline
\end{tabular}




\section{Age, human performance and physical employment standards}

Glen P. Kenny ${ }^{1}$, Herbert Groeller ${ }^{2}$, Ryan McGinn $^{1}$ and Andreas D. Flouris ${ }^{1,3}$

${ }^{1}$ Human Environmental Physiological Research Unit, Faculty of Health Sciences, University of Ottawa, Ontario, Canada; ${ }^{2}$ Centre for Human and Applied Physiology, School of Medicine, University of Wollongong, Wollongong, NSW, Australia; ${ }^{3}$ FAME Laboratory, Department of Exercise Science, University of Thessaly, Trikala, Greece.

Running Title: Aging and physical work capacity

\section{Address for Correspondence:}

Glen P. Kenny

University of Ottawa

125 University Ave.

Ottawa, ON, Canada, K1N 6N5

Phone: +16135625800 ext. 4282

Fax: +1 6135625497

e-mail: gkenny@uottawa.ca 


\section{ABSTRACT}

The proportion of older workers has increased substantially in recent years with over $25 \%$ of the Canadian labour force aged $\geq 55$ years. Along with chronological age comes age-related declines in functional capacity associated with impairments to the cardiorespiratory and muscular systems. As a result, older workers are reported to exhibit reductions in work output and in the ability to perform and/or sustain the required effort when performing work tasks. However, research has presented some conflicting views on the consequences of aging in the workforce as physically demanding occupations can be associated with improved or maintained physical function. Furthermore, the current methods for evaluating physical function in older workers often lack specificity and relevance to the actual work tasks, leading to an underestimation of physical capacity in the older workers. Nevertheless, industry often lacks the appropriate information and/or tools to accommodate the aging workforce particularly in the context of physical employment standards. Ultimately, if appropriate workplace strategies and work performance standards are adopted to optimize the strengths and protect against the vulnerability of the aging workers, they can perform as effectively as their younger counterparts. Our aim in this review is to evaluate the impact of different individual (including physiological decline, chronic disease, lifestyle and physical activity) and occupational (including shift work, sleep deprivation, and cold/heat exposure) factors on the physical decline of older workers, and therefore the risk of work-related injuries or illness.

Keywords: aging, worker, work ability, functional capacity, health, fitness, exercise. 


\section{INTRODUCTION}

The demographics of the labour force are rapidly changing such that the proportion of workers aged 45 and older has increased by as much as $50 \%$ in the past 20 years in most industrialized countries (CDC 2012b). By 2030, the number of people $\geq 65$ years in the United States is projected to double, representing $20 \%$ of the total US population (CDC 2012b). In Canada, one person out of four in the labour force is $\geq 55$ years. Notably, worker age in many physically demanding occupations has risen at an even greater pace (Statistics Canada 2011). These trends raise many serious questions about our readiness and ability to protect our aging workers especially given the observation that physically demanding jobs may accelerate the age-related reductions in work capacity.

Aging has been defined as the "persistent decline in the age-specific fitness components of an organism due to internal physiological deterioration" (Rose 1991) and as a "complex biological process in which changes at molecular, cellular, and organ levels result in a progressive, inevitable, and inescapable decrease in the body's ability to respond appropriately to internal and/or external stressors" (Chodzko-Zajko et al. 1987). In the context of the older worker, these age-related changes invariably lead to changes in work capacity and performance ultimately affecting worker health and safety.

The complex relationship between age and occupational safety and health is not well understood especially in the context of physically demanding occupations (e.g. firefighting, mining, electrical utilities work, construction and others). Some reports have indicated that older workers experience fewer work-related accidents (Shishlov et al. 2011; Schwatka et al. 2012), although others suggest that they have a proportionally higher frequency of injury (and fatalities) than their younger counterparts (Lowery et al. 1998; Kemmlert et al. 2001). Irrespective of these 
differences, age-related changes in physical and cognitive function place older workers at greater risk of experiencing more severe workplace injuries and illnesses, and therefore more absent days (Farrow et al. 2012). However, to date there remains a paucity of information related to age-specific injury rates in highly demanding occupations such as firefighting, mining, electrical utilities work. In general, age-related reductions in physical work capacity are first observed between the ages of 40 and 50, albeit changes can occur as early as 20 years. These reductions are largely attributed to decreases in in aerobic ( $\sim 40 \%$ between the ages of 30 and 65 years) and musculoskeletal ( $\sim 15$ to $20 \%$ by 60 years of age) capacity which can be exacerbated by chronic health disorders and may in part explain the increased incidence of job-related injuries and fatalities (Figure 1) (Kenny et al. 2008). However, the extent of the decline in physical functioning, and therefore the risk of work-related injuries or illness, is dependent on a myriad of individual factors including lifestyle, level of physical activity and fitness, and general health.

According to the Centers for Disease Control and Prevention, the age of 40 years is used as a starting point for the "older worker" (CDC 2012a), albeit other agencies and organizations have used ages up to 55 years as the threshold. As recently as 2013, the Bureau of Labour Statistics reported the median age of all industry personnel to be 42.4 years, with up to a median of 50 years for workers in industrial manufacturing and up to 47.2 years in coal mining (BLS 2013). Subsequently, of all the industry workers, $45 \%$ are $\geq 45$ years with $22 \%$ and $5 \%$ being $\geq 55$ and $\geq 65$ years, respectively. Importantly, the proportion of workers $\geq 65$ years reached as high as $20 \%$ in industries of agriculture and forestry (BLS 2013). Collectively, it is clear that while older workers can be classified as those in the middle stages of their career (i.e., $~ 40$ years), our definition of the "older worker" must also shift with the rapidly increasing age of the workforce. 
While age-related changes in physical and cognitive function are inescapable, they do not consistently lead to poor worker performance and productivity. In fact, if appropriate workplace strategies are adopted to build upon the strengths and protect against the vulnerabilities of workers as they age, older workers can perform as effectively as their younger counterparts (Zavanela et al. 2012). However, in many situations industry lacks the appropriate information and/or tools to implement appropriate work management strategies to protect their vulnerable workers. For example, the American Conference of Governmental Industrial Hygienists Threshold Limit Values (TLVs) is commonly used for managing work activities in hot conditions. The TLVs refer to the daily level of heat stress to which all workers may be exposed with low risk of adverse effects. The values are based on the assumption that nearly all young, well hydrated and acclimatized workers should be able to function effectively under a given working condition without exceeding a core temperature of $38.5^{\circ} \mathrm{C}$. Within its application, the issue is whether this limit provides adequate protection for all workers including the most vulnerable, namely the older worker especially those with chronic health conditions (e.g. diabetes, hypertension, obesity, etc.). Employers have a duty to take every reasonable precaution to develop policies and procedures to protect all workers, including the most vulnerable; however, more research is required in the consequences of work-related factors on worker health, performance and productivity in order to achieve this objective.

By anticipating and adjusting for the physical changes experienced by older workers through well-organized and supported work-site health management strategies, aging workers can remain healthy while performing physically demanding jobs safely. Many employers are aware that such efforts are necessary, but most have not yet addressed them in large part because of a lack of knowledge and information available for guidance. This is best evidenced by an 
overwhelming lack of physical employment standards across numerous disciplines wherein employees are held to the same standards regardless of characteristics which may impact their capacity such as age, sex and/or the presence of chronic health conditions. Employers who establish age-friendly workplaces that promote and support the work ability of employees as they age are likely to be more successful in maintaining worker safety and productivity, ultimately optimizing their competitiveness and sustainability. However, in many occupations, especially those requiring high sustained physical efforts, it may not be possible to accommodate the work demands with the capacities of the workers. In such situations it will be necessary to assess if a worker is 'Fit for Duty' and therefore physically capable of performing the required job/task safely without undue levels of physical strain and fatigue.

The task of identifying whether or not an older worker may be able to perform a given job is made more difficult by the fact that there is high degree of diversity in the jobs performed within a given occupation. There are few age-related studies to date that have examined how measures of decrease in physiological function (e.g. cardiorespiratory fitness, musculoskeletal capacity along with flexibility, eye sight, and hearing) can be used to determine the changes in work ability especially in older workers. Moreover, while there have been studies examining the energy demands in physically demanding occupations (Kenny et al. 2012; Meade et al. 2015), few have examined these responses in the context of the older worker. While changes in the work environment and/or conditions can be made to suit the functional capacity of the aging worker, a good understanding of the nature of the work performed and the work environment would be required to identify possibilities for work accommodations. This should include programs aimed at the maintenance of functional capacity which may be implemented via 1) a high quality health surveillance program (e.g., in-service health assessments) over the career of 
the worker, especially in those performing physically demands jobs (Sluiter 2006) and 2) a workplace health-enhancing physical activity strategy to manage the health and functional capacity of the worker. The inclusion of such a program will help to prevent and manage the decrements in physical work capacities that the aging worker will experience.

In the following sections, we will examine in greater detail the physiological changes associated with age-related decrements in physiological function and the impact it can have on a worker's ability to perform physically demanding jobs. Specifically, we will outline the recent evidence detailing the age-related decrements in cardiorespiratory and musculoskeletal function and the additive effects of chronic health conditions. In addition, we will present the net consequences of the age-related decrements in functional capacity, the additional occupational challenges for older workers, and the challenges faced by employers along with postulated strategies that could be implemented in order to facilitate the older and more vulnerable workers to continue meeting occupational demands. 


\section{PHYSIOLOGICAL FUNCTION AND AGING}

As a consequence of the aging workforce, employers are facing complex issues concerning older workers that are continuing to work despite pronounced impairments in physiological function (Figure 1). While workers must possess a certain level of physical ability in order to perform various tasks to remain as contributing members to their employer, workplaces must be tasked with providing a work environment and work hours that accommodate older individuals. However, the increasing proportion of older workers has not yet been met with a decline in occupational demands, making it increasingly difficult for workers to continue meeting productivity requirements and safety standards. For example, a recent study reported that electrical utilities workers did not alter work output based on age. Even at higher levels of physiological strain, work output remained constant which lead to $75 \%$ of workers exceeding the TLV for core body temperature (Meade et al. 2015). While tasks associated with many physically demanding jobs are at particular risk for increasing work-related injury in older adults, even repetitive sedentary tasks (reading, typing, etc.) may cause limb strain in such workers.

In the workforce, the primary contributor to reductions in work ability, productivity, and absence due to illness is the presence of health problems and/or susceptibility to injury (Leijten et al. 2014). Older adults are at greater risk for a number of afflictions including chronic health conditions and work-related injuries which can lead to a reduced maximal capacity. Consequently, older workers may be required to work at a much greater percentage of their maximum ability. Noteworthy, the level of risk varies greatly between individuals and depends on several factors including genetics, lifestyle, and current health status. Taken together, it would be most effective for workplaces and older individuals to establish guidelines collectively for 
workers and develop realistic expectations regarding assigned tasks, productivity standards, and time-at-work to optimize day-to-day operations and efficiency.

\section{Age-related decrements in physical function}

Aging in humans is closely associated with progressively increased risk for chronic health conditions and functional disability (Figure 1). However, it is important to note that even healthy older adults exhibit important decrements in physical function which can impact their ability to perform at work. Organ systems (i.e., cardiovascular, respiratory, and muscular systems) may decline by as much as $\sim 2 \%$ per year after age 30 (Sehl et al. 2001). More recently, Nelson et al. (2010) reported an average decline of $8 \%$ in maximum oxygen consumption (a strong predictor of all-cause mortality) per decade between the ages of 30 and 69 years in healthy adults with jobs as corporate managers or administrators. In a subgroup of individuals followed longitudinally $(\sim 7.3$ years $)$ and given individualized health and fitness counselling, the decline in maximum oxygen consumption was decreased - although not eliminated - to only $0.4 \%$ per year (or $4 \%$ over a decade) (Nelson, Petersen et al. 2010). As a result, the average physical work capacity of a 65-year old can be reduced by up to $\sim 50 \%$ compared to an average 25 -year old worker (Ilmarinen et al. 1999). On the other hand, research has clearly indicated that the age-related changes in physiological function can be dampened by various factors including physical activity. This notion has brought to light the concepts of biological (i.e., changes to the organ systems) versus chronological aging (i.e., changes associated with age and the passing of time) in humans such that the numerical age of an individual (e.g. 70 years of age) does not always equate to a given level of physical capacity. For example, recent studies by Leyk and colleagues (Leyk et al. 2009; Leyk et al. 2010) indicated that performance losses are strongly related to a 
sedentary lifestyle rather than chronological aging. However, it is important to note that while regular physical activity (among many other factors) may delay the process of age-related decrements in physical function, there is currently no way to halt it indefinitely.

\section{Cardiovascular function}

Systolic and diastolic function. It is well established that cardiac remodeling (i.e., ventricular hypertrophy) along with impairments in contractility and relaxation develop progressively with increasing age. Importantly, the consequences of these alterations do not appear at rest (Martin et al. 2015). In contrast, during physical work the impairments in contractility in older adults lead to a diminished increase in ejection fraction by up to $20 \%$ and a consequent reduction in cardiac output compared to younger individuals (Hawkins et al. 2003; Martin et al. 2015). Similar to systolic function, changes in diastole only become evident during episodes of physical work. In young adults, early diastole is associated with rapid ventricular filling and modest atrial contraction whereas older adults exhibit a $\sim 50 \%$ reduction in early diastolic filling during physical exertion (Groeller 2008; Lucas et al. 2015). However, by producing a more vigorous atrial contraction, older adults are able to maintain similar enddiastolic volumes relative to their younger counterparts (Groeller 2008). Therefore, blood delivery to working muscles can be markedly reduced in older adults, leading to a reduction in work ability and performance which may be exacerbated when work is performed in hot environments as the competition for blood flow between the working muscles and the skin is heightened.

Cardiac and vascular responsiveness. The sympathetic branch of the autonomic nervous system governs cardiac contractility and output as well as peripheral resistance (i.e., afterload). 
However, the age-related increase in resting sympathetic tone (i.e., reduced capacity to increase during stress) combined with the reduced sensitivity to changes in sympathetic stimulation limits the ability of the aging heart to increase heart rate during exertion (Hawkins and Wiswell 2003; Bellew et al. 2005; Fleg et al. 2005) which ultimately reduces the capacity to increase blood supply to the working muscles. Consequently, older adults rely more heavily on increasing stroke volume for increases in cardiac output relative to their younger counterparts (Martin, Farrah et al. 2015). Alternatively, changes in aging blood vessels can manifest as a marked reduction in elasticity (Greenwald 2007) and thereby increased stiffness which leads to an increase in cardiac afterload. Furthermore, recent findings have indicated that vasodilator capacity can be reduced by up to $45 \%$ in older adults due to decreased nitric oxide and prostaglandin production from the endothelium (Schrage et al. 2007). Collectively, the reductions in cardiac output and in the capacity of vasodilation can lead to substantial perturbations in the delivery of oxygen to the working tissues and ultimately work ability.

\section{Pulmonary function}

While the trends of pulmonary function associated with aging are highly variable, optimal pulmonary function typically occurs between 20-25 years of age. With age comes pronounced impairments in compliance of the chest wall and lung tissue associated with increased chest wall stiffness due to rib joint calcification (Estenne et al. 1985) and reduced parenchymal elasticity (Janssens 2005; Ramly et al. 2015). While these opposing changes will result in similar total lung capacities between young and older individuals (Vaz Fragoso et al. 2012), they do lead to reductions in ventilatory efficiency (Spirduso 2005; Kenny et al. 2008). For instance, older workers can have increased work of breathing by up to $175 \%$ relative to their 
younger counterparts during physical exertion at $60 \%$ of cardiac reserve (Chaunchaiyakul et al. 2004). Furthermore, older adults can present with a marked decrease in respiratory muscle strength and endurance by $\sim 75 \%$ which can impair efforts to cough and eliminate secretions (Kenny et al. 2008; de Oliveira-Maul et al. 2013). Consequently, older workers are at particular risk when working in environments with poor air quality.

Despite similarities in total lung capacity throughout the lifespan, there are important changes in air exchange that occur. Residual volume is markedly increased by the reduction in lung elasticity, and the combination of air trapping and lung hyperinflation lead to increases in functional residual capacity. Among the consequences of these changes include greater levels of alveolar collapse due to lower inspiratory and expiratory pressures (Groeller 2008; Vaz Fragoso and Gill 2012) as well as reduced forced vital capacity (Vaz Fragoso and Gill 2012). In particular, forced vital capacity has been shown to decrease by $\sim 30 \mathrm{~mL}$ per year $(\sim 25 \mathrm{~mL}$ per year for females) or 4-5\% per decade (Marks 2002; Hollenberg et al. 2006). Ultimately, agerelated changes in lung volumes can lead to differences in gas exchange due to impaired ventilation-perfusion matching (i.e., suboptimal distribution of ventilation) (Janssens 2005; Ramly et al. 2015) as well as increased alveolar dead space (American Thoracic Society 2003; Ramly et al. 2015). It is important to note; however, that these changes can be vastly exacerbated by smoking.

\section{Body composition}

The changes in body composition associated with increasing age have been reported to largely account for the differences in physical functioning and work ability. In particular, older adults tend to have greater body fat and less muscle mass. These changes are multifactorial such that 
they exhibit components from changes in hormone signalling, metabolic activity, dietary intake, and physical activity. Consequently, increasing age is associated with increases in body mass index (BMI), which in turn is associated with poor muscle quality and incidence of chronic disease. In the context of work ability, higher body fat is related to pronounced decreases in physical capacity as well as higher rates of disability in workers and is said to more strongly explain the reduction in physical performance compared to the change in thigh muscle area (Tseng et al. 2014).

The accumulation of body fat in the visceral tissues, muscles, and blood vessels of aging humans is strongly associated with poor physical performance and disability (Brady et al. 2014). Notably, obesity has been regarded as the leading cause of disability among older adults (Ogden et al. 2012). Approximately $40 \%$ of older adults are obese $\left(B M I>30 \mathrm{~kg} / \mathrm{m}^{2}\right.$ ) and such individuals are $\sim 60 \%$ more likely to develop marked functional declines (Schaap et al. 2013). Obesity also puts older adults at particular risk for cardiovascular disease, diabetes, and cancer which indirectly exacerbate the functional decline and impact work ability (Chang et al. 2012). As detailed below, older adults often exhibit reductions in cross-sectional muscle area (i.e., sarcopenia). While both sarcopenia and obesity can independently impair physical function, a recent study implicated older adults with sarcopenic obesity to have the greatest declines in physical function and that the prevalence of this phenotype is rapidly growing (Brady et al. 2014). Importantly, females tend to have reduced physical function relative to males throughout the lifespan and this partly explains the discrepancy in work ability between older males and females (i.e., females have a lower baseline physical capacity) (Vincent et al. 2010). These sexrelated differences may be further explained by a combination of higher body fat, greater muscle 
fat infiltration, and/or lower muscle mass in older females; however, recent work indicates that the rate of decline between sexes is similar (Tseng et al. 2014).

\section{Musculoskeletal capacity}

Noticeable declines in muscular strength and endurance become evident as late as 65 years such that a deterioration of $\sim 25 \%$ compared to those at 30 years of age is observed (Gall et al. 2004). The primary factor underlying the impairments in musculoskeletal capacity is lost muscle mass (i.e., sarcopenia) (Bellew et al. 2005; Delmonico et al. 2009). Sarcopenia can begin at the age of 30 and lead to $\sim 30 \%$ reduced cross-sectional muscle area by age 65 (Doherty 2001). These reductions appear to be more pronounced in the lower extremities and are attributed to a combined decline in the number and size of skeletal muscle fibres (Marks 2002; Kenny et al. 2008). The major contributor to age-related sarcopenia is the simultaneous neuromuscular alterations such that there is selective age-related denervation of motor units, particularly type II fibres (Callahan et al. 2011; Miller et al. 2013). As a result, there is a proportional shift towards type I muscle fibres and an increase in the size of the remaining motor units which subsequently increases the activation threshold of the muscle and decreases the speed of contraction (Miller et al. 2014). Functionally, sarcopenia and denervation can lead to marked reductions in walking speed and endurance (Ostchega et al. 2004; Kenny et al. 2008) as well as stability (Brill et al. 2000; Kenny et al. 2008), all of which are crucial requirements for adequate work ability in many industries. Fortunately, regular resistance training has been shown to delay and even reverse the progression of sarcopenia and denervation in aging adults (Parente et al. 2008; Harber et al. 2009; Toth et al. 2012; Miller et al. 2014). 
Muscular strength and endurance are equally (or even more strongly) correlated with work ability compared to cardiorespiratory fitness (Kenny et al. 2008). Age-related sarcopenia and denervation are associated with a rate of decline in muscular strength of $\sim 12-15 \%$ per decade after age 50 (Doherty 2001; Kamel 2003) or up to 5\% per year (Aoyagi et al. 1992; Savinainen et al. 2004), albeit differences exist between isometric and concentric muscular strength. The most relevant for workers in construction and mining is isometric strength, which appears to remain stable until age 40 (American College of Sports Medicine 2010; Dodds et al. 2014) followed by a decline of $\sim 1.0-1.5 \%$ per year (Savinainen et al. 2004b; Bellew et al. 2005; Spirduso 2005). Notably for older females, the transition from pre- to post-menopause has been related to particularly high rates of decline in grip and pinch strength which is associated with the rapid fall of ovarian hormone production (Doherty 2003). In contrast, concentric muscular strength is most relevant for many other workers including firefighters and nurses. Aging typically presents a decline in concentric muscular strength by $8-10 \%$ per decade (Walker et al. 2014) and is particularly observed in the lower extremities as mentioned above. Taken together, age-related sarcopenia and selective denervation can cause particular reductions in musculoskeletal capacity and thereby markedly impair work ability in older workers.

Together with these deteriorations in musculoskeletal capacity, aging is associated with a progressive decline in flexibility, coordination and balance - albeit the rate of change is highly dependent upon the individual's general physical fitness and state of health. Age-related decrements in strength, which are exacerbated by reduced levels of physical activity and /or fitness, can negatively impact balance (Brill et al. 2000; Ostchega et al. 2004). Importantly, reductions in lower body muscle strength and power as well as balance are considered important contributors to injuries such as falls. Many physically demanding occupations require the 
execution of complex motor tasks that require the precise coordination and integration of multiple large muscle groups (e.g., the trunk, lower limbs and upper limbs). Aging can affect the activation pattern such that the recruitment of muscles is negatively impacted leading to reduced muscle coordination and balance (Fujiyama et al. 2012; Marques et al. 2015). While the underlying mechanism(s) underpinning this response remains unclear, age-related decreases in muscle strength (and muscle atrophy especially in older adults $>60$ years of age) may be in an important contributor (Ikezoe et al. 2015). Furthermore, as recently reported, age-related changes in postural control may degrade the integrated coordination of sensory feedback and motor execution (Yeh et al. 2015). For workers engaged in the performance of complex physically demanding tasks, a greater attention/focus is required to maintain the appropriate level of postural and cognitive activity. Relative to their younger counterparts, older adults differ in their ability to perform these competitive tasks (i.e., postural and cognitive) such that their ability to prioritize the tasks is compromised thereby increasing their risk for loss of balance and therefore fall-related injuries (Brown et al. 1999; Bernard-Demanze et al. 2009). Moreover, older adults have a reduced ability to stabilise posture following an external perturbation as it is more demanding of their attention (Brown al. 1999). Consequently, older workers experience greater sprains/strains injuries to the ankle/foot/toes, knees/lower legs, and multiple body parts caused by falls as compared to younger workers (Choi 2015). The implementation of health management programs which include an aerobic and resistance training component can preserve or augment postural stability and dynamic balance (Bellew et al. 2005; Holviala et al. 2006; Paterson et al. 2010) - factors which can invariably affect a worker's functional ability and risk of work-related injuries (e.g. falls) (Holviala et al. 2006; Manini et al. 2007; Bernard-Demanze et al. 2009). Additionally health management programs that integrate flexibility training 
interventions can enhance joint range of motion in various joints leading to improvements in joint and postural stability and therefore enhanced functional ability (Paterson and Warburton 2010).

\section{Cardiorespiratory fitness}

The maintenance of cardiorespiratory fitness is one of the most important aspects of healthy aging in humans and can markedly affect all-cause mortality (Kokkinos et al. 2011) as well as workers' ability to perform, especially physically demanding tasks. However, there is a clear progressive age-related decline in cardiorespiratory fitness (most commonly assessed by maximal oxygen consumption, $\mathrm{VO}_{2 \max }$ ) that begins at age 30 (Ilmarinen 2001; Fleg et al. 2005). Reports have indicated that the rate of decline in $\mathrm{VO}_{2 \max }$ can be $\sim 5-15 \%$ per decade (Hawkins and Wiswell 2003; Bellew, Symons et al. 2005; Crawford et al. 2010) or $0.25-1.04 \mathrm{ml} \cdot \mathrm{kg}^{-1} \cdot \mathrm{min}^{-1}$ per year (Gall and Parkhouse 2004; Savinainen et al. 2004b; Bellew et al. 2005), ultimately leading to a decrease in cardiorespiratory fitness of up to $60 \%$ by the age of 70 . Cardiorespiratory fitness depends upon two fundamental concepts: the adequate delivery of oxygen to the metabolically active tissues as well as adequate oxygen extraction and utilisation. The decline in $\mathrm{VO}_{2 \max }$ with age can be explained by both concepts given the age-related changes to the involved organ systems (i.e., heart, lungs, and skeletal muscles). The impaired increase in cardiac output together with the changes in pulmonary compliance as well as sarcopenia manifest as reductions in $\mathrm{VO}_{2 \max }$. These changes seen in older adults can result in progressive and marked reductions in work ability as well as performance of tasks that are both physically and non-physically demanding (Ritvanen et al. 2007; Kenny et al. 2008). Importantly, regular physical activity has been shown to blunt, albeit not entirely prevent (down to $0.5 \%$ per year), 
the decline in $\mathrm{VO}_{2 \max }$ in older adults in a dose-dependent manner (Arias et al. 2015; Jebens et al. 2015).

Sex-differences. Males and females generally adhere to a similar trajectory of a decline in physiological function with advancing age (Tseng et al. 2014); however, this is inconsistent for the rate of decline in cardiopulmonary function (Hollenberg et al. 2006). While the authors reported that absolute $\mathrm{VO}_{2 \max }$ in females was only $77 \%$ of that for males, this difference was eliminated (down to 5\%) when expressed as a function of kilograms of lean body mass. In addition, females exhibited a lower rate of decline in $\mathrm{VO}_{2 \max }$ compared to males and this was attributed primarily to the changes in maximal heart rate associated with increasing age (Hollenberg et al. 2006). Therefore, while males and females usually start with a different baseline aerobic capacity (i.e., males have a greater $\mathrm{VO}_{2 \max }$ relative to females), the rate of decline in fitness and therefore functional capacity is greater in males. 


\section{THE IMPACT OF AGE IN PHYSICALLY DEMANDING ENVIRONMENTS}

Despite the pronounced age-related mental and/or physical decline, some reports indicate that work performance is not affected until age 70 (Tuomi et al. 2001; Farrow and Reynolds 2012). While this may reflect benefits of job experience, the productivity losses for both sexes in physically demanding jobs is much more apparent and is accompanied by greater relative incidence of work-related accidents and/or injuries (Tuomi et al. 2001; Farrow and Reynolds 2012). Data from several large-scale US surveys indicate increased absenteeism in each decade from $\sim 5$ to $\sim 18$ days for workers aged $20-24$ and $\geq 65$ years, respectively (Rogers et al. 2005). Moreover, workers $\geq 65$ years have a work-related fatality rate $\sim 3$-fold higher than workers aged 16-64 years (Pratt 2003). The following sub-sections discuss the impact of age-related changes in physiological function and work ability on the work output in physically demanding jobs.

\section{Impact of cardiorespiratory fitness}

Several occupational studies have shown that cardiorespiratory fitness declines progressively in both men and women by $\sim 10 \%$ per decade (Figure 1) (Gall and Parkhouse 2004; Savinainen et al. 2004a; Crawford et al. 2010) which can markedly impair the work ability of older workers (Ritvanen et al. 2007; Kenny et al. 2008). Nevertheless, the evidence remains inconclusive as reduced cardiorespiratory function in older workers is not always associated with increased fatigue or attenuated work output (Crawford et al. 2010). The most likely explanation involves the factor of seniority which allows older workers to select lighter and less demanding tasks which is supported by powerline technicians whereby the older workers performed less pole work and more groundwork compared to young workers (Parkhouse et al. 2004). In doing so, the older workers tended to adopt the role of a supervisor (which included less physical work) to 
compensate for the age-associated decline in cardiorespiratory fitness (Parkhouse and Gall 2004). In turn, the older workers were able to transfer their knowledge and expertise to the younger workers.

\section{Impact of musculoskeletal deteriorations}

Aging is accompanied by muscle remodeling and attenuated strength as detailed above (Figure 1). In construction- and mining-type occupations the most relevant type of strength is isometric, which remains stable until age 40 followed by a decline of $\sim 1-5 \%$ per year (Savinainen et al. 2004b; Bellew et al. 2005; Spirduso 2005). On the other hand, concentric muscular strength, which is most relevant for many other workers including firefighters and nurses, has been shown to decline by $8-10 \%$ per decade (Vilela et al. 2015) particularly in the lower extremities. These deteriorations are mainly due to an age-related shift from type II to type I muscle fibres along with marked sarcopenia and are associated with pronounced impairments in work ability and performance (Doherty 2001; Miller et al. 2013). In addition, there is a $\sim 10 \%$ increase in the prevalence of musculoskeletal disease in male workers between the ages of 50 and 54 (Tuomi et al. 1991). Of particular note, workers in physically demanding jobs tend to exhibit greater prevalence of musculoskeletal diseases and are diagnosed earlier than workers in less challenging jobs (Koskela 1997).

Despite these musculoskeletal deteriorations, it remains unclear whether they are associated with attenuated work output (Crawford et al. 2010). Indeed, longitudinal data demonstrate that older workers have attenuated strength and flexibility whereas cross-sectional studies report relatively few differences from young workers for job-specific tasks (Schibye et al. 2001; Gall and Parkhouse 2004). Nevertheless, it is clear that older workers require longer and 
more frequent rest periods compared to younger workers especially when performing physically and/or psychologically demanding tasks, monotonous work, and when working for $>42$ hours/week (Devereux et al. 2009; Crawford et al. 2010). Moreover, older workers exhibit increased postural sway when standing normally (Punakallio 2003) which is exacerbated when wearing protective equipment compared to young workers (Punakallio et al. 2003). Therefore, the reductions in muscle mass in the lower extremities together with neuromuscular changes can lead to marked reductions in walking speed and endurance (Ostchega et al. 2004; Kenny et al. 2008) as well as stability (Brill et al. 2000; Kenny et al. 2008). Collectively, these findings indicate that musculoskeletal deteriorations in the aging worker likely impacts work ability and performance for physically demanding work. Importantly, musculoskeletal disorders and stress have recently been identified as the most commonly reported new cases of self-reported ill health with workers $\geq 45$ years showing the highest prevalence (Health and Safety Executive 2008; Leijten et al. 2013; Leijten et al. 2014).

\section{Impact of chronic health disorders on physical function}

It is important to consider that aging is also associated with increased risk for developing chronic health disorders. The aging workforce and that 2 out of 3 older adults have one or more chronic health disorders according to the National Center for Health Statistics (2010). Therefore, more consideration is warranted for the extent to which chronic health disorders can impact work ability. Obesity is the most prevalent chronic health disorder in older workers in industrialized countries (Park 2009; Jordan et al. 2015) and can cause marked functional limitations and reduced work ability (Figure1) (Capodaglio et al. 2010). Consequently, obese workers tend to report higher job strain, higher psychological demands, feelings of low social support and other 
markers associated with greater lost-time injuries (i.e., increased absenteeism) (Capodaglio et al. 2010). Indeed, the heaviest workers file twice as many health claims as workers of normal weight with cost and number of days lost being strongly associated with BMI (Ostbye et al. 2007). Interestingly, health claims of obese workers were even higher in high-risk occupations with high physical demands and ergonomic stress (Ostbye et al. 2007; Kuehl et al. 2012). Ultimately, obesity is reported to reduce participation in the workforce (Degli Esposti et al. 2006) and is associated with increased absenteeism, disability, and health claims (Han et al. 2009) as well as attenuated salaries (Baum et al. 2004) and productivity (Bhattacherjee et al. 2003) with a 13-fold increase in lost working days and 11-fold increase in compensation claims (Tunceli et al. 2006).

Individuals with obesity and other chronic health disorders are less likely to continue working compared to their healthy counterparts (Baanders et al. 2002) and up to 58\% those that are employed report difficulties in performing their work (Lerner et al. 2000). Naturally, the prevalence of chronic health disorders increases with age and the highest prevalence of illness (and therefore, absenteeism) are among workers are males aged 55-64 years and females aged 45-59 years (Health and Safety Executive 2008). Cardiopulmonary impairments and type 2 diabetes are among the most notable to cause marked decreases in work ability (Leijten et al. 2013; Leijten et al. 2014) and are associated with higher rates of heat illness when such individuals are exposed to hot environments (Kenny et al. 2010). For example, older men and women with type 2 diabetes showed marked attenuations in whole-body heat loss (by 60\%) during a 60 -min work bout in a moderately hot environment (i.e., $30^{\circ} \mathrm{C}$ ) compared to nondiabetics matched for age, sex, anthropometry, and cardiorespiratory fitness (Kenny et al. 2013). Importantly, this study reported that the differences in the capacity to dissipate heat were evident 
as early as $15 \mathrm{~min}$ into the work bout and continued into the recovery period. These findings have particularly important implications for occupations with physical jobs since several lines of evidence demonstrate that hyperthermia and heat stress lead to attenuated work output in individuals of all ages (Flouris 2011; Kenny et al. 2014). In addition, these effects may be exacerbated in occupations where protective clothing is worn (e.g., mining, armed forces, automotive/athletic settings) as the clothing will further impair the rate of heat loss. Despite this, there is a lack of information relating to the direct effects on work ability and to strategies for employers to better protect and serve these workers.

\section{Managing functional decline through physical activity}

Though the acquired job experience and more efficient use of resources of older workers may be able to compensate for reduced work output, these adjustments are possible only when there is flexibility in job content (Laflamme et al. 1995). Unfortunately, in several occupations, especially in physically demanding jobs, such adjustments are not possible. This highlights the importance of mitigating obesity and supporting fitness to preserve work ability and delay biological aging in older workers despite continued chronological aging.

Several daily tasks in physically demanding jobs can be a sufficient stimulus to promote or maintain cardiorespiratory fitness. For instance, an $86-\mathrm{kg}$ individual tending a furnace in a steel mill expends $\sim 648 \mathrm{kcal} \cdot \mathrm{h}^{-1}$ (with similar values reported for other physically demanding jobs), which is analogous to jogging on a flat surface at $8.4 \mathrm{~km} \cdot \mathrm{h}^{-1}$ (McArdle et al. 2001). However, the majority of older workers are physically inactive during leisure time. This is particularly true for blue-collar workers, who generally have the most physically demanding jobs (Ilmarinen 2001). Moreover, blue-collar workers commonly have $\geq 1$ unhealthy habits including 
smoking, alcohol abuse and/or unhealthy diet (Flouris et al. 2012). It has been well established that interventions to improve/maintain the overall health and functional capacity (i.e., cardiorespiratory fitness and musculoskeletal capacity) in older workers can simultaneously enhance work ability (Ilmarinen and Rantanen 1999; Tuomi et al. 2001). For example, the inclusion of programs for specific health behaviours (e.g. nutrition, smoking, and alcohol use) may be beneficial (Ilmarinen 2001; Tuomi et al. 2001; Bohle et al. 2010; Flouris et al. 2010; Borah et al. 2015). Furthermore, the involvement of health experts (e.g. kinesiologists, nutritionists, nurses, physicians) can maximize the impact of interventions geared towards improving functional capacity (Borah et al. 2015; Kramer et al. 2015; Vilela et al. 2015). Importantly, effective interventions should be age-specific if measureable changes in work ability are to be achieved for all workers (Ilmarinen and Rantanen 1999).

Ultimately, when performed regularly, aerobic training, resistance training and/or their combination can improve cardiorespiratory and musculoskeletal function, and delay age-related decrements in physical functioning and work capacity. Aerobic training leads to substantial improvements in cardiorespiratory fitness in previously non-exercising healthy older adults whereas resistance training can induce marked increases in lean body mass and muscle strength/performance and consequently, functional capacity (Ramirez-Campillo et al. 2014). Individuals who remain physically active and maintain lean body mass experience a lower rate of decline in physical capacity compared to their sedentary counterparts (Hawkins and Wiswell 2003). In general, the implementation of workplace interventions involving physical activity have yielded important positive outcomes for workers, including improved health, fitness and health related quality of life (Zavanela et al. 2012). While the level of physical activity at work can be an important determinant affecting a workers overall physical work capacity and health 
(Arias et al. 2015), the addition of a physical training program performed in the workplace or during the worker's leisure times can increase an individual's work ability regardless of differences in the level of physical activity while on the job (Ohta et al. 2004). However, as recent evidence suggests the workplace health-enhancing physical activity strategy must be welldesigned, multi-faceted and provide expert guidance and support to the worker to ensure a positive outcome (Viester et al. 2014).

\section{Factors affecting work ability in older adults}

Shift/night work and sleep deprivation. In young workers, rotating shift work and nonstandard hours (i.e., night shifts) are detrimental for health, physiological function, sleep, work performance, and personal life (Bohle et al. 2010). Despite 24 and 12\% of older male and females workers report having frequent night shifts, (Bohle et al. 2010) there remains a paucity of information regarding the age-related effects of shift work. Aging is known to impact circadian rhythms such that the adjustment to night work is hindered (i.e., older workers sleep earlier at night) (Costa et al. 2007). In line with these findings, the critical age for intolerance to night work is $\sim 45-50$ years (Costa et al. 2008). Consequently, older workers may be unable to sleep adequately following a night shift, thereby increasing the risk of sleep disorders and deprivation (Costa and Di Milia 2008). Furthermore, it is important to highlight that shift work and irregular working hours may have adverse effects on the work ability of older workers. Indeed, shift workers appear to have a lower work ability compared to day workers, a finding that is further exacerbated in the older population (Costa 2005). This may be due to the greater need for recovery for older workers in order to effectively perform their work tasks (Ilmarinen 
and Rantanen 1999). Figure 2 provides a list of recommendations based on the available evidence for the management of shift workers over the age of 50 .

Work in hot environments. Healthy humans maintain core temperature at near constant level $\left(\sim 37^{\circ} \mathrm{C}\right)$ regardless of environmental conditions. However, age-related impairments in whole-body heat loss are reported to occur as early as age 40. Specifically, a recent study showed that individuals $\geq 40$ years store $60-80 \%$ more heat than younger counterparts aged $20-31$ years after two hours of moderate-intensity (rate of heat production of $400 \mathrm{~W}$ ) intermittent work (Larose et al. 2013). This was supported in a follow-up study identifying impairments in the capacity of middle-aged and older adults to dissipate heat that occur during work in both dry and humid heat stress conditions (Larose et al. 2014). Indeed, while all age groups in this study stored almost double the amount of heat when ambient humidity was increased from dry ( 20\%) to moderately humid $(60 \%)$, the middle-aged and older adults still demonstrated proportionally greater heat storage (by $\sim 38 \%$ ). In addition, these differences are dependent upon metabolic heat load (i.e., intensity of physical activity or work) such that marked reductions in the physiological capacity to dissipate heat were observed at a metabolic heat load $\geq 400 \mathrm{~W}$ and $\geq 325 \mathrm{~W}$ for older males and females respectively (Stapleton et al. 2015b; Stapleton et al. 2015a). The authors also noted that the age-related impairments were influenced by fitness such that middle-aged adults with high fitness showed high heat loss (i.e., comparable to their younger counterparts), while middle-aged adults with low fitness showed low heat loss (i.e., comparable to their older counterparts) (Stapleton et al. 2015b; Stapleton et al. 2015a).

Work in cold environments. Similar to the impairments in heat loss, older workers (particularly $>60$ years) have a diminished capacity to maintain core temperature during cold exposure (Blatteis 2012). The mechanisms for this include attenuated cutaneous thermal 
sensitivity and subjective thermal perception when exposed to cold environments (Blatteis 2012). Consequently, older adults require intense cold stimuli before activating their protective mechanisms. In addition, the skin vasoconstrictor response to cold is reduced in older adults along with the amount of heat generated by shivering and non-shivering thermogenesis due to age-related atrophy of the skeletal muscles (Florez-Duquet et al. 1998) and of brown adipose tissue (Flouris et al. 2015). As a result, metabolic heat production of many older workers in the cold may not offset heat loss which can lead to reduced peripheral blood flow and even hypothermia. Taken together, older workers are at greater risk for decreased work ability in hot and cold environments (which include various climates around the world as well as specific work environments). 


\section{ASSESSMENT AND ADAPTATIONS OF OLDER ADULTS}

\section{Physical performance measures and aging workers}

Assessing physical performance can determine the effectiveness of personnel with respect to the occupational demands. Indeed, physical assessments have the standard within the military since the mid- $19^{\text {th }}$ century to determine the suitability of non-incumbent personnel for training activities (Knapik et al. 2004). Discrete assessments of physical fitness, such as a single repetition maximum squat, are commonly assigned to cover specific physical domains of performance (e.g. muscular strength), from which normative values are obtained to characterise a population. The physical performance domains of muscular strength, endurance and range of motion are essential attributes that decline with age, but are necessary for the maintenance of occupational performance and work ability (Pohjonen 2001a; Jebens et al. 2015).

Range of motion. Aging is associated with deteriorations in the functional range of joint motion in the general population and older workers (Savinainen et al. 2004b; ACSM 2010); however, the magnitude of change varies considerably. For example, a longitudinal investigation of 45 municipal workers over a 16-year period observed a $20-25 \%$ decrease in spinal and trunk range of motion (Savinainen et al. 2004b). In contrast, a cross-sectional study of 750 employees observed inconsistent changes in cervical $(\sim 10 \%$ decline after age 60$)$ and spinal (no change in females and a clear increase in males) range of motion across four decades (Cote et al. 2014). Noteworthy, the range of motion values from Cote et al. (2014) were markedly different compared to reference values which may indicate a cohort effect or reflect differing methods of assessment for range of motion between studies (Yoo et al. 2011).

Muscular strength. The retention of the isometric strength in older workers may be influenced by job characteristics such as the intensity of the work. Specifically, one study 
observed workers undertaking heavy manual labour to maintain grip strength over a 16-year period whereas those employees performing light tasks showed reductions with age (Savinainen et al. 2004a). In addition, aging workers have shown improved resistance to fatigue during isometric tasks (Avin et al. 2011) along with improved static endurance of the shoulder, neck, and lumbar muscles, and isotonic endurance of the trunk extensors which (Jebens et al. 2015). Alternatively, isokinetic knee and trunk extensor endurance show no change over four decades in manufacturing workers (Cote et al. 2014).

The findings described above clearly indicate that older workers do not follow the normal pattern of the age-related decline in musculoskeletal capacity. Furthermore, it is important to acknowledge that isometric contractions rarely represent the complexity of movement or force required when performing occupational tasks (Holsgaard Larsen et al. 2007). As demonstrated by Gall and Parkhouse (2004), a significant age-related decline was noted in isometric strength; however, when participants then repeated the isometric assessment with a joint position appropriate for performing a work-related task (i.e., the elbow was extended and the wrist placed in ulnar deviation), no age-related change in muscle strength was observed (Gall and Parkhouse 2004). Thus, physical assessments can often lack the specificity required to truly quantify occupational-directed musculoskeletal function, and thereby underestimate work ability.

It is well accepted that a pronounced age-related reduction in upper (35\%) and lower (30\%) limb strength occurs over 4 decades (ACSM 2010). Noteworthy, a 10-15\% decline in leg press strength over a similar time period was reported for older workers (Cote, Kenny et al. 2014). In fact, the males within this investigation that spanned a 40 -year age range had leg press strength ratios $\sim 1.5$ times greater than those reported for the general population, while female workers had markedly lower limb strength ratios $(0.81-0.81)$ relative to the general population 
(1.44-0.99). In contrast, older female workers exhibited no detectable age-related decline in lower limb strength compared to a $30 \%$ reduction in the general female population (ACSM 2010). While still unclear, this divergence in occupational and normative strength values may be explained by the prolonged and persistent physical demands placed on the workers (Cote et al. 2014).

Cardiorespiratory fitness. Unlike musculoskeletal function, the age-related decline in cardiorespiratory fitness in the general population after age 30 is paralleled in older workers (Gall and Parkhouse 2004; Jebens et al. 2015). Thus, cardiorespiratory fitness is reduced irrespective of the daily occupational demands faced at by older workers (Schibye et al. 2001; Jebens et al. 2015). Along these lines, physically demanding jobs are also not associated with better protection from cardiovascular disease (Holtermann et al. 2010) which may be impacted by sedentary lifestyle outside of work and other detrimental habits such as smoking, alcohol abuse, and poor diet.

\section{Physical performance in healthy older workers}

Chronologically speaking, an individual at 60 years has aged 20 years more than an individual of 40 years. However, chronological age does not necessarily provide an indication of how the progression of time has affected the body structures and regulatory systems or distinguish the interaction with the environment and disease (biological aging). For example, the chronic adoption of poor health behaviours such as sedentary lifestyle, smoking, poor diet, and substance abuse will exacerbate the effects of biological aging, such that two individuals in their 60s may have widely disparate levels of aging, disease and physical function. This variance in biological and chronological aging may explain the level of heterogeneity in the physical performance 
scores of older adults (Cote et al. 2014; Jebens et al. 2015) and thus limits our ability to use chronological age as a marker for work ability and productivity (Dewhurst 2015). For example, shoulder press and leg press strength showed a 10- and 2-fold difference respectively between the lowest and highest mass lifted in a group of Norwegian workers aged 45-60 (Savinainen et al. 2004b; Jebens et al. 2015). Indeed, some older males were observed to have superior absolute upper- and lower-limb strength relative to co-workers who were up to 30 years younger (Jebens et al. 2015). Clearly there exists a complex interaction between genetics and long-term health behaviours that can act to minimise or accelerate biological aging (Cote et al. 2014).

Although older workers are at increased risk for work-related injury (Loeppke et al. 2013; Fox et al. 2015), physical work may help to preserve work ability in older adults such that population-based age standards could underestimate the ability of an older worker (Cote et al. 2014). These interactions have been termed the 'healthy worker effect' which is thought to be a common confounding factor in occupational research (Li et al. 1999). The initial employment screening, retention requirements, environment regulations, employee services, and employer organisation size can have a substantial impact upon the health of the worker. Specifically, employers often employ methods to screen and select employees based on minimum health and physical employment standards (Taylor et al. 2003). Consequently, employees may have health and physical fitness which exceed those of the general population (Li and Sung 1999). Moreover, this selection bias may extend as the worker ages allowing for increased work ability and therefore sufficient health and capacity to meet occupational demands (Hagen et al. 1993).

It is important to note that the healthy worker effect can protect some workers from afflictions associated with biological aging, albeit this effect is not consistent throughout occupations or organizations. Workplace restrictions of negative health behaviours (e.g. 
smoking) and the facilitation of positive health behaviours (e.g. dietary or physical activity advice) are reported to have a substantial impact upon the health and wellness of employees (Li and Sung 1999). However, not all employers have the capacity to deliver a comprehensive health program. In such situations, the responsibility may fall to the government with a socialised health care system to fill such gaps for ethical (i.e., worker protection and safety) and economical reasons (i.e., worker retention). Large organisations are four-fold more likely to have preemployment physical examinations and five-fold more likely to provide periodic medical examinations than smaller employers (Wilcosky et al. 1987). Furthermore, older adults that are retired tend to exhibit rapid reductions in work ability and functional capacity due to increased rates of disease and/or disability which may have been the cause of retirement (Robroek et al. 2013). Ultimately, older workers with physically engaging occupations may be healthier than the general population; however, information regarding the conditions allowing for the "health worker effect" is sparse and requires further research in order to be better defined.

\section{The work ability index}

Work ability is the assessment of one's available resources to meet occupational demands in their working environment. The ability of an employee to be productive at work can be assessed in numerous ways (van den Berg et al. 2009) with the most common and widely accepted measure being the Work Ability Index (Ilmarinen 2001). This index is based on the i) physical and ii) mental demands of the individual at work, iii) their psychological resources and iv) capacity, v) the presence of disease and vi) the associated restrictions as well as the vii) prediction of future work ability. The summed scores from each of the seven areas in the questionnaire produce a score up to 49 to identify work ability as poor (7-27), moderate (28-36), 
good (37-43) or excellent (44-49) (van den Berg et al. 2009). High functional capacity is required for a score of good or excellent whereas lower functional capacity will yield lower ratings with scores of $\sim 16$ and $\sim 25$ indicating disease and disability, respectively (Pohjonen 2001b; Wind et al. 2009). Thus, work ability is a multi-dimensional construct encompassing physical tasks along with environmental and personal factors that influence worker health (Ilmarinen 2001).

The influence of health and age. There is a strong association between perceived health status, work ability and disability (Krause et al. 1997; Pohjonen 2001b). Indeed perceived health status has been observed to be a stronger predictor of retirement with disability than actual disease prevalence determined by a medical examination (Krause et al. 1997). Similarly, diagnosis of any chronic disease is associated with a lower work ability index (von Bonsdorff et al. 2011a). For example, a poor work ability index was reported in $60 \%$ of blue- and white collar middle-aged workers (44-58 years) with musculoskeletal disease and only $16 \%$ with an excellent work ability index (von Bonsdorff et al. 2011a). There is typically strong associations between the presence of musculoskeletal and/or psychosomatic symptoms and reduced work ability (Pohjonen 2001b) with the greatest differences observed in individuals with psychological and/or physical health problems (van de Vijfeijke et al. 2013; Leijten et al. 2014). However, it is clear that interactions between physical and mental health exist as some individuals with a chronic disease(s) still obtain a superior work ability index (van de Vijfeijke et al. 2013).

Although work ability diminishes with age (Camerino et al. 2006; Alavinia et al. 2007), the rate of decline is influenced substantially by the nature of the occupational tasks (Ilmarinen 2009; von Bonsdorff et al. 2011b). For instance, jobs with lower strain and increased employee support tend to delay the age-related reductions in work ability for up to 28 years (von 
Bonsdorff et al. 2011b). Therefore, the implementation of strategies aimed to promote work ability in younger workers are critical for long-term productivity, continued competence and minimizing socioeconomic strain from functional loss after retirement (Ilmarinen and Rantanen 1999). However, the work ability index may not be directly comparable across age groups. Due to a relatively brief exposure to the occupation, younger workers may overestimate their current work ability which then amplifies the perceived losses in work ability over time (Ilmarinen 2009). Thus, modified normative values may better characterise work ability in less experienced employees and thereby allow for more accurate comparisons as a function of worker experience (Kujala et al. 2005).

Functional capacity. Age-related declines in functional capacity tend to accelerate after the age of 45 (Kenny et al. 2008; Soer et al. 2012). Despite this, the absolute physical demands of occupational tasks remain unchanged irrespective of worker age and attributes (Louhevaara 1999) such that a given task will represent a progressively greater percentage of an aging worker's peak functional capacity (Ilmarinen 2001; Jebens et al. 2015). Surprisingly, this has no apparent impact on the ability of the worker to meet the energetic demands of their tasks (Soer et al. 2012; Jebens et al. 2015). However, higher work intensities will expose the older workers to greater relative strain, and therefore increased risk of injury due to overexertion and fatigue (McGill 1997). For example, construction workers have recently been reported to expend $\sim 1.1$ $\mathrm{LO}_{2} \cdot \mathrm{min}^{-1}$ which corresponds to $\sim 25 \%$ and $\sim 33 \%$ of $\mathrm{VO}_{2 \max }$ for younger and older workers, respectively (Jebens et al. 2015). For the older workers, this relative work rate approaches and may exceed the upper limits $\left(30-35 \% \mathrm{VO}_{2 \max }\right)$ of relative energy expenditure recommended for an 8-hour shift (Ilmarinen 1992a). Although a higher energy expenditure may seem beneficial for workers, the age-related functional decline appears to be exacerbated in the most physically 
demanding occupations (Savinainen et al. 2004a; Seitsamo et al. 2007; Holtermann et al. 2010; von Bonsdorff et al. 2011b). In fact, a 17-year study followed 6000 employees from jobs that were physically demanding. After retirement when worked-related strain was removed, employees reported a marked increase in well-being and in the ability to perform daily activities (Seitsamo et al. 2007). Noteworthy, while this improvement following retirement may be linked with the removal of work-related strain, a recent study by Miranda et al. (2015) noted that other workplace stressors included smoking and sedentary lifestyle. These combination of stressors have an overall detrimental effect on worker health and the fact that they appear to affect younger workers more strongly (Miranda et al. 2015) implies that employers must act quickly to prevent a progressively worsening level of work ability among workers of all ages.

\section{Managing the health and safety of our aging workforce}

Changing workforce demographics has required employers and employees to re-examine attitudes and assumptions regarding the productivity and suitability of the older worker (Dewhurst 2015). For example, older workers may benefit from the workplace accommodations which are designed to assist people with disabilities (Kampfe et al. 2008); however, their use is limited as workers assume that their declining health is an unavoidable consequence of aging (Tishman et al. 2012). The retention of older workers is even becoming necessary for employers such that they can no longer rely upon a steady influx of younger works to meet production needs (Oude Hengel et al. 2012). Consequently, employers are being faced with the need to adopt long-term strategies for managing and maintaining their workforce.

Is improved safety criteria required? Given that reduced physical capacity will invariably increase the risk of injury (Walker et al. 2014), age-specific physical performance standards are 
the traditional manner to accommodate older workers. This approach has been criticized for being grossly inadequate in guaranteeing that workers are capable of meeting occupational demands (Fullagar et al. 2015). Despite such limitations, employers are expected to ensure that workers are physically able to perform their duties safely and effectively (Payne et al. 2010; Jamnik et al. 2013). One of the most effective prevention strategies is the adoption interventions to minimize biological aging, albeit only 20 out of $400(5 \%)$ surveyed employers were implementing such strategies for older workers (Silverstein 2008). Clearly, huge efforts are needed to encourage employers to commit to health promotion and intervention programs that will improve the health, safety and productivity of their workers.

Consideration of workplace ergonomics is of critical importance for retention and safety of employees by ensuring that demanding tasks are assigned to capable workers (Silverstein 2008) and would benefit all employees regarding personal health and overall productivity (Alavinia et al. 2007; Fox et al. 2015). For example, limiting precision requirements in a repetitive manual handling task can be of great benefit for physical work capacity (Collier et al. 2014). Similarly, an ergonomically friendly environment through managing noise, lighting, falls, and physical hazards can minimize the risk of injury in older workers (Loeppke et al. 2013; Fox et al. 2015) along with implementing maximum workloads during a work shift. In particular, relative work rates that do not exceed $50 \%$ and $33 \%$ of peak oxygen consumption with and without rest periods respectively are recommended (Ilmarinen 1992b). Although older workers can sustain prolonged submaximal work rates, intermittent peak loading may prevent task completion (Ilmarinen 1992b; Fox et al. 2015). Along these lines, increasing opportunities for part-time employment may also minimise deterioration in physiological capacity due to fatigue as a result of longer recovery between shifts and /or shorter work shifts (Ilmarinen 1992b; 
Loeppke et al. 2013). It cannot be ignored; however, that certain occupations including emergency and military services may lack the necessary flexibility in work tasks to modulate work intensity for different workers. Such rigid constructs tend to negatively impact worker retention as the capacity to tolerate peak loads progressively decreases with age. In such cases, the promotion of teamwork and/or rotating schedules may be effective in retaining experienced employees despite their reduced work ability (Perera et al. 2015) and prevent early retirement (Oude Hengel et al. 2012; Loeppke et al. 2013).

\section{Fit for duty: considerations of age?}

Given the rising number of vulnerable workers (i.e., older and/or with chronic disease), proper assessment of employee health is increasingly important. These assessments and the determination of "fit for duty" standards aim to identify those workers particularly vulnerable to the work hazards, or with insufficient health (Sluiter et al. 2007). It is crucial for these measures to be specific to avoid unnecessary relief of duties and sensitive enough to identify workers in significant danger. Unfortunately, pre-employment health examinations reportedly lack effectiveness and efficiency (Westerholm et al. 1997) and the use widely criticised age-based physical work standards to evaluate physical capacity (Fullagar et al. 2015). Others have recommended pro-active health checks, monitoring and functional assessments at fixed intervals to prevent and manage chronic disease among workers along with assisting to remain "fit for duty" (Loeppke et al. 2013). Subsequently, employee suitability assessments can focus on the safe completion of work tasks rather than the extent of biological aging (Sluiter and FringsDresen 2007). Such an approach where increased clarity is provided by the employer as to the minimum physical standards necessary for employment would ensure that older workers are not 
disadvantaged where limits based on chronological age may exist. For example, physically demanding occupations such as those associated with firefighting and lifeboat rescue have traditionally employed chronological age-defined retirement limits (Reilly et al. 2005; Sluiter and Frings-Dresen 2007; Jamnik et al. 2010). The appropriateness and/or justification of such an approach requires further scrutiny. In the interim, the identification and implementation of jobspecific minimum physical employment standards would ensure that age-specific work limits as well as age of retirement would be defined solely on the basis of an individual's functional or physical work ability without the bias inherent with pre-determined chronological age limits (Reilly and Tipton 2005; Sluiter and Frings-Dresen 2007; Jamnik et al. 2010).

In addition to defining the minimum work employments standards, the approach used to assess a worker's ability to perform the job must be appropriate. A recurring problem in many occupations is the frequent misrepresentation of work ability by using irrelevant and overly simplified tests (e.g. handgrip strength) to verify or assess a worker's functional capacity to perform a specific job. The use of task simulations allows for a more appropriate evaluation of employee suitability to meet and/or exceed occupational demands. This approach would also take into account differences and/or changes in work efficiency that are typically observed with workers with differing levels of training and/or years of experience (e.g., young versus older workers). In the context of the aging worker, some have observed a marked decline in task simulation performance with age (Strating et al. 2010; Walker et al. 2014), yet others have reported no change (Fullagar et al. 2015). Importantly, age-related impairments in physical performance, should be considered in the context of meeting the minimum physical requirements to safely perform work duties. For example, Soer et al. (2012) observed younger (20-39 years) and older workers (50-59 
years) to have a similar required lifting capacity to meet occupational demands classified as medium or heavy. In contrast, substantial disparity was found in peak performance values (Strating et al., 2010), albeit the individuals deemed incapable were not identified.

Therefore, although there are effects of age (i.e., biological and chronological) upon the capacity of the worker, it is critical for employers to consider the mandate for physical work standards to be without discrimination (i.e., independent of age) (Tipton et al. 2013). In order to meet this requirement of "all inclusive" minimum work standards, they must be based on: i) job analysis, ii) the demands inherent to the job, irrespective of age and/or work experience, iii) the lowest physical performance levels necessary (i.e., work ability) and, iv) a test of work ability that is a valid representation of critical or important work demands (Payne and Harvey 2010; Jamnik et al. 2013; Tipton et al. 2013). As such, the accommodations for employees should not be based solely on altering the current functional performance standards. Rather, focus should aim to modify the environment to reduce physical demands, provide alternative (i.e., taskspecific) physical assessments, and facilitate improvements in employee physical capacity (i.e., health interventions) (Jamnik et al. 2013; Tipton et al. 2013). Ultimately, the strategies to optimise functional capacity of workers should be emphasized instead of chronological agebiased physical performance thresholds.

\section{Future directions: a need for physical employment standards}

Considering the increasing age of the worker combined with the functional limitations that are commonly associated with older adults, it should follow that the development of physical employment standards with specific adjustments for worker age be prioritized. However, to date no such standards have been developed and research aimed at creating such standards is largely 
absent which has left numerous critical knowledge gaps. For example, while the older worker may be less able to maintain a reduced work output over longer periods of time due to impairments in aerobic capacity, they have the advantage of years of experience which allows for increased efficiency. Therefore, employing age-based work-rest ratios may facilitate the productivity of the older worker, albeit no such studies have examined this potentially beneficial algorithm. Moreover, while the 2nd International Conference on Physical Employment Standards summarized the current knowledge in various fields of employment standards, there appeared to be an overwhelming discrepancy in the knowledge for the aging worker. Specifically, several reviews in this special issue of Applied Physiology of Nutrition and Metabolism summarize the topics of legal and human rights issues, medical standards, the validity and reliability of existing tests and standards, and the current methods by which to set standards along with the effects of load carriage, protective clothing, extreme environments, stress, nutrition, and sex on human performance and the development of physical employment standards. However, none of these reviews have specifically addressed the impact of aging which highlights the extent to which the literature has ignored this important and growing segment of workforce (i.e., the aging worker).

The process of chronological and biological aging is an area of intense research; however, the relationship of aging and occupational health and safety is relatively less well understood. Workers engage in diverse environments, each with unique physical and psychosocial demands that present considerable challenges for effective research. Crosssectional research designs are common, but there is a dearth of appropriately powered, longitudinal research of meaningful duration for the study of aging in occupational settings. Despite these limitations there are numerous avenues of occupational aging research that require 
further exploration including the characteristics of work which cause a decline in functional capacity, the establishment of strategies to accommodate vulnerable workers, and the complex interactions between occupational, physical, and psychological stress on work ability. However, merely recognising and studying the decline in physical function in aging workers is of minimal utility unless it is aligned with meaningful interventions and workplace adjustments (Figure 3). Furthermore, each area of subject matter experts including government, researchers, employers and workers have an obligation to enhance the integration of older employees in the workforce. Through close collaboration, we can produce a more productive, worker friendly environment that is independent of factors affecting vulnerability including age and chronic disease.

\section{Conclusion}

The global population is aging along with the average worker age in many occupations. Although, the chronological aging is inescapable, biological aging may be blunted with good health habits. However, the effects of aging are not well understood with respect to work ability and functional capacity. Occupational task demands often lack the necessary flexibility to optimise worker productivity, health, and safety, irrespective of different factors of vulnerability including age and chronic disease. Indeed it is often the most physically demanding occupations that may lead to the greatest declines in physical function. The development of physical employment standards are likely to help address the developing challenge of facilitating older workers; however, there is much work to be done before such standards can be established. In addition, given the considerable variation in the age-related decline of functional capacity, a critical challenge lies ahead to develop robust workplace interventions, that not only preserve the economic viability of the employer, but also maintain employee health, safety, and work ability. 


\section{CONFLICTS OF INTEREST}

The authors have no conflicts of interest to declare. 


\section{REFERENCES}

Alavinia, S.M., van Duivenbooden, C., and Burdorf, A. 2007. Influence of work-related factors and individual characteristics on work ability among Dutch construction workers. Scand J Work Environ Health 33: 351-7.

American College of Sports Medicine, A. 2010. ACSM's health-related physical fitness assessment manual. Philadelphia: Wolters Kluwer Lippincott Williams and Wilkins.

American Thoracic Society, A.C.o.C.P. 2003. ATS/ACCP Statement on cardiopulmonary exercise testing. Am J Respir Crit Care Med 167: 211-77.

Arias, O.E., Caban-Martinez, A.J., Umukoro, P.E., Okechukwu, C.A., and Dennerlein, J.T. 2015. Physical activity levels at work and outside of work among commercial construction workers. J Occup Environ Med 57: 73-8.

Avin, K.G. and Law, L.A. 2011. Age-related differences in muscle fatigue vary by contraction type: a meta-analysis. Phys Ther 91: 1153-65.

Baanders, A.N., Rijken, P.M., and Peters, L. 2002. Labour participation of the chronically ill. A profile sketch. Eur J Public Health 12: 124-30.

Baum, C.L., 2nd and Ford, W.F. 2004. The wage effects of obesity: a longitudinal study. Health Econ 13: 885-99.

Bellew, J.W., Symons, T.B., and Vandervoort, A.A. 2005. Geriatric fitness: Effects of aging and recommendations for exercise in older adults. Cardiopulm Phys Ther J 16: 20-31.

Bernard-Demanze, L., Dumitrescu, M., Jimeno, P., Borel, L., and Lacour, M. 2009. Age-related changes in posture control are differentially affected by postural and cognitive task complexity. Curr Aging Sci 2: 139-49.

Bhattacherjee, A., Chau, N., Sierra, C.O., Legras, B., Benamghar, L., Michaely, J.P., Ghosh, A.K., Guillemin, F., Ravaud, J.F., and Mur, J.M. 2003. Relationships of job and some individual characteristics to occupational injuries in employed people: a community-based study. J Occup Health 45: 382-91.

Blatteis, C.M. 2012. Age-dependent changes in temperature regulation - a mini review. Gerontology 58: 289-95.

BLS 2013. Labor force statistics from the current population survey: Bureau of Labour Statistics

Bohle, P., Pitts, C., and Quinlan, M. 2010. Time to call it quits? The safety and health of older workers. Int J Health Serv 40: 23-41. 
Borah, B.J., Egginton, J.S., Shah, N.D., Wagie, A.E., Olsen, K.D., Yao, X., and Lopez-Jimenez, F. 2015. Association of worksite wellness center attendance with weight loss and health care cost savings: Mayo Clinic's experience. J Occup Environ Med 57: 229-34.

Brady, A.O., Straight, C.R., and Evans, E.M. 2014. Body composition, muscle capacity, and physical function in older adults: an integrated conceptual model. J Aging Phys Act 22: 441-52.

Brill, P.A., Macera, C.A., Davis, D.R., Blair, S.N., and Gordon, N. 2000. Muscular strength and physical function. Med Sci Sports Exerc 32: 412-6.

Brown, L.A., Shumway-Cook, A., and Woollacott, M.H. 1999. Attentional demands and postural recovery: the effects of aging. J Gerontol A Biol Sci Med Sci 54: M165-71.

Callahan, D.M. and Kent-Braun, J.A. 2011. Effect of old age on human skeletal muscle forcevelocity and fatigue properties. J Appl Physiol 111: 1345-52.

Camerino, D., Conway, P.M., Van der Heijden, B.I., Estryn-Behar, M., Consonni, D., Gould, D., and Hasselhorn, H.M. 2006. Low-perceived work ability, ageing and intention to leave nursing: a comparison among 10 European countries. J Adv Nurs 56: 542-52.

Capodaglio, P., Castelnuovo, G., Brunani, A., Vismara, L., Villa, V., and Capodaglio, E.M. 2010. Functional limitations and occupational issues in obesity: a review. Int J Occup Saf Ergon 16: 507-23.

CDC 2012a. Aging workers at higher risk of death, severe injury, conference report suggests ways to keep workers healthy and productive: Centres for Disease Control and Prevention.

CDC 2012b. Older employees in the workplace: Centre for Disease Control and Prevention. Doc 1 p6.

Chang, H.J., Kim, J.W., Ju, S.Y., and Go, E.S. 2012. How do the work environment and work safety differ between the dry and wet kitchen foodservice facilities? Nutr Res Pract 6: 366-74.

Chaunchaiyakul, R., Groeller, H., Clarke, J.R., and Taylor, N.A. 2004. The impact of aging and habitual physical activity on static respiratory work at rest and during exercise. Am J Physiol Lung Cell Mol Physiol 287: L1098-106.

Chodzko-Zajko, W.J. and Ringel, R.L. 1987. Physiological fitness measures and sensory and motor performance in aging. Exp Gerontol 22: 317-28.

Choi, S.D. 2015. Aging Workers and Trade-Related Injuries in the US Construction Industry. Saf Health Work 6: 151-5.

Collier, B.R., Holland, L., McGhee, D., Sampson, J.A., Bell, A., Stapley, P.J., and Groeller, H. 2014. Precision markedly attenuates repetitive lift capacity. Ergonomics 57: 1427-39.

Costa, G. 2005. Some considerations about aging, shift work and work ability.In: G. Costa, W. Goedhard, and J. Ilmarinen Eds., Assessment and Promotion of Work Ability, Health, and Well- 
being of Ageing Workers. Proceedings of the 2nd International Symposium on Work Ability. 1820 October, 2004. Verona, Italy, pp. 67-72. San Diego, CA: Elsevier.

Costa, G. and Di Milia, L. 2008. Aging and shift work: a complex problem to face. Chronobiol Int 25: 165-81.

Costa, G. and Sartori, S. 2007. Ageing, working hours and work ability. Ergonomics 50: 191430 .

Cote, M.P., Kenny, A., Dussetschleger, J., Farr, D., Chaurasia, A., and Cherniack, M. 2014. Reference values for physical performance measures in the aging working population. Hum Factors 56: 228-42.

Crawford, J.O., Graveling, R.A., Cowie, H.A., andDixon, K. 2010. The health safety and health promotion needs of older workers. Occup Med Lond 60: 184-92.

de Oliveira-Maul, J.P., de Carvalho, H.B., Miyuki Goto, D., Mendonca Maia, R., Flo, C., Barnabe, V., Franco, D.R., Benabou, S., Rodrigues Perracini, M., Jacob-Filho, W., Nascimento Saldiva, P.H., Lorenzi-Filho, G., Rubin, B.K., and Kondo Nakagawa, N. 2013. Aging, diabetes, and hypertension are associated with decreased nasal mucociliary clearance. Chest 143: 1091-7.

Degli Esposti, E., Sturani, A., Valpiani, G., Di Martino, M., Ziccardi, F., Rita Cassani, A., Baraccani, C., Gentile, M., Puglia, M.G., and Degli Esposti, L. 2006. The relationship between body weight and drug costs: An Italian population-based study. Clin Ther 28: 1472-81.

Delmonico, M.J., Harris, T.B., Visser, M., Park, S.W., Conroy, M.B., Velasquez-Mieyer, P., Boudreau, R., Manini, T.M., Nevitt, M., Newman, A.B., and Goodpaster, B.H. 2009. Longitudinal study of muscle strength, quality, and adipose tissue infiltration. Am J Clin Nutr 90: 1579-85.

Devereux, J.J. and Rydstedt, L.W. 2009. Does the older workforce with high work demands need more recovery from work.In: P. Bust Eds., Contemporary Ergonomics, pp. 189-196. London: Taylor and Francis.

Dewhurst, E. 2015. Are older workers past their sell-by-date? A view from UK age discrimination law. MLR 78: 189-215.

Dodds, R.M., Syddall, H.E., Cooper, R., Benzeval, M., Deary, I.J., Dennison, E.M., Der, G., Gale, C.R., Inskip, H.M., Jagger, C., Kirkwood, T.B., Lawlor, D.A., Robinson, S.M., Starr, J.M., Steptoe, A., Tilling, K., Kuh, D., Cooper, C., and Sayer, A.A. 2014. Grip strength across the life course: Normative data from twelve british studies. PLoS One 9: 1-15.

Doherty, T.J. 2001. The influence of aging and sex on skeletal muscle mass and strength. Curr Opin Clin Nutr Metab Care 4: 503-8.

Estenne, M., Yernault, J.C., and De Troyer, A. 1985. Rib cage and diaphragm-abdomen compliance in humans: effects of age and posture. J Appl Physiol 1985 59: 1842-8. 
Farrow, A. and Reynolds, F. 2012. Health and safety of the older worker. Occup Med Lond 62: 4-11.

Fleg, J.L., Morrell, C.H., Bos, A.G., Brant, L.J., Talbot, L.A., Wright, J.G., and Lakatta, E.G. 2005. Accelerated longitudinal decline of aerobic capacity in healthy older adults. Circulation 112: 674-82.

Florez-Duquet, M. and McDonald, R.B. 1998. Cold-induced thermoregulation and biological aging. Physiol Rev 78: 339-58.

Flouris, A.D. 2011. Functional architecture of behavioural thermoregulation. Eur J Appl Physiol 111: 1-8.

Flouris, A.D. and Dinas, P.C. 2015. Impact of regular exercise on classical brown adipose tissue. Clin Endocrinol Oxf 83(4):591-3.

Flouris, A.D., Metsios, G.S., Carrillo, A.E., Jamurtas, A.Z., Stivaktakis, P.D., Tzatzarakis, M.N., Tsatsakis, A.M., and Koutedakis, Y. 2012. Respiratory and immune response to maximal physical exertion following exposure to secondhand smoke in healthy adults. PLoS One 7: e31880.

Flouris, A.D., Metsios, G.S., Jamurtas, A.Z., and Koutedakis, Y. 2010. Cardiorespiratory and immune response to physical activity following exposure to a typical smoking environment. Heart 96: 860-4.

Fox, R.R., Brogmus, G.E., and Maynard, W.S. 2015. Aging Workers \& Ergonomics: A fresh perspective. Prof Saf 60: 33-41.

Fujiyama, H., Hinder, M.R., Schmidt, M.W., Garry, M.I., andSummers, J.J. 2012. Age-related differences in corticospinal excitability and inhibition during coordination of upper and lower limbs. Neurobiol Aging 33: 1484 e1-14.

Fullagar, H.H., Sampson, J.A., Mott, B.J., Burdon, C.A., Taylor, N.A., and Groeller, H. 2015. Employment standards for Australian urban firefighters. Part 4: Physical aptitude tests and standards. J Occup Environ Med 57:1092-7.

Gall, B. and Parkhouse, W. 2004. Changes in physical capacity as a function of age in heavy manual work. Ergonomics 47: 671-87.

Greenwald, S.E. 2007. Ageing of the conduit arteries. J Pathol 211: 157-72.

Groeller, H. 2008. The physiology of aging in active and sedentary humans.In: N.A.S. Taylor and $\mathrm{H}$. Groeller Eds., Physiological bases of human performance during work and exercise, pp. 289-306: Churchill Livingstone.

Hagen, K.B., Vik, T., Myhr, N.E., Opsahl, P.A., and Harms-Ringdahl, K. 1993. Physical workload, perceived exertion, and output of cut wood as related to age in motor-manual cutting. Ergonomics 36: 479-88. 
Han, E., Norton, E.C., and Stearns, S.C. 2009. Weight and wages: fat versus lean paychecks. Health Econ 18: 535-48.

Harber, M.P., Konopka, A.R., Douglass, M.D., Minchev, K., Kaminsky, L.A., Trappe, T.A., and Trappe, S. 2009. Aerobic exercise training improves whole muscle and single myofiber size and function in older women. Am J Physiol Regul Integr Comp Physiol 297: R1452-9.

Hawkins, S.A. and Wiswell, R.A. 2003. Rate and mechanism of maximal oxygen consumption decline with aging. Sports Med 33: 877-888.

Health and Safety Executive 2008. Self-reported work-related illness and workplace injuries in 2006/07: results from the Labour Force Survey. Sudbury, UK.

Hollenberg, M., Yang, J., Haight, T.J., and Tager, I.B. 2006. Longitudinal changes in aerobic capacity: implications for concepts of aging. J Gerontol A Biol Sci Med Sci 61: 851-8.

Holsgaard Larsen, A., Caserotti, P., Puggaard, L., and Aagaard, P. 2007. Reproducibility and relationship of single-joint strength vs multi-joint strength and power in aging individuals. Scand J Med Sci Sports 17: 43-53.

Holtermann, A., Mortensen, O.S., Burr, H., Sogaard, K., Gyntelberg, F., and Suadicani, P. 2010. Physical demands at work, physical fitness, and 30-year ischaemic heart disease and all-cause mortality in the Copenhagen Male Study. Scand J Work Environ Health 36: 357-65.

Holviala, J.H., Sallinen, J.M., Kraemer, W.J., Alen, M.J., and Hakkinen, K.K. 2006. Effects of strength training on muscle strength characteristics, functional capabilities, and balance in middle-aged and older women. J Strength Cond Res 20: 336-44.

Ikezoe, T., Nakamura, M., Shima, H., Asakawa, Y., and Ichihashi, N. 2015. Association between walking ability and trunk and lower-limb muscle atrophy in institutionalized elderly women: a longitudinal pilot study. J Physiol Anthropol 34: 31.

Ilmarinen, J. 1992a. Job design for the aged with regard to decline in their maximal aerobic capacity: Part I - Guidelines for the practitioner Int J Ind Ergon 10: 53-63.

Ilmarinen, J. 1992b. Job design for the aged with regard to decline in their maximal aerobic capacity: Part II - The scientific basis for the guide. Int J Ind Ergon 10.

Ilmarinen, J. 2009. Work ability--a comprehensive concept for occupational health research and prevention. Scand J Work Environ Health 35: 1-5.

Ilmarinen, J. and Rantanen, J. 1999. Promotion of work ability during ageing. Am J Ind Med Suppl 1: 21-3.

Ilmarinen, J.E. 2001. Aging workers. Occup Environ Med 58: 546-52. 
Jamnik, V., Gumienak, R., and Gledhill, N. 2013. Developing legally defensible physiological employment standards for prominent physically demanding public safety occupations: a Canadian perspective. Eur J Appl Physiol 113: 2447-57.

Jamnik, V.K., Thomas, S.G., Burr, J.F., and Gledhill, N. 2010. Construction, validation, and derivation of performance standards for a fitness test for correctional officer applicants. Appl Physiol Nutr Metab 35: 59-70.

Janssens, J.P. 2005. Aging of the respiratory system: impact on pulmonary function tests and adaptation to exertion. Clin Chest Med 26: 469-84.

Jebens, E., Mamen, A., Medbo, J.I., Knudsen, O., and Veiersted, K.B. 2015. Are elderly construction workers sufficiently fit for heavy manual labour? Ergonomics 58: 450-62.

Jordan, G., Nowrouzi-Kia, B., Gohar, B., and Nowrouzi, B. 2015. Obesity as a Possible Risk Factor for Lost-time Injury in Registered Nurses: A Literature Review. Saf Health Work 6: 1-8.

Kampfe, C.M., Wadsworth, J.S., Mamboleo, G.I., and Schonbrun, S.L. 2008. Aging, disability, and employment. Work 31: 337-44.

Kemmlert, K. and Lundholm, L. 2001. Slips, trips and falls in different work groups--with reference to age and from a preventive perspective. Appl Ergon 32: 149-53.

Kenny, G.P. and Flouris, A.D. 2014. The human thermoregulatory system and its response to thermal stress.In: F. Wang and C. Gao Eds., Protective Clothing: Managing Thermal Stress, pp. 319-349. Cambridge, UK: Woodhead Publishing Ltd. in association with The Textile Institute.

Kenny, G.P., Stapleton, J.M., Yardley, J.E., Boulay, P., and Sigal, R.J. 2013. Older Adults with Type 2 Diabetes Store More Heat during Exercise. Med Sci Sports Exerc 45: 1906-14.

Kenny, G.P., Vierula, M., Mate, J., Beaulieu, F., Hardcastle, S.G., and Reardon, F. 2012. A field evaluation of the physiological demands of miners in Canada's deep mechanized mines. J Occup Environ Hyg 9: 491-501.

Kenny, G.P., Yardley, J., Brown, C., Sigal, R.J., and Jay, O. 2010. Heat stress in older individuals and patients with common chronic diseases. CMAJ 182: 1053-60.

Kenny, G.P., Yardley, J.E., Martineau, L., and Jay, O. 2008. Physical work capacity in older adults: implications for the aging worker. Am J Ind Med 51: 610-25.

Knapik, J.J., Reynolds, K.L., and Harman, E. 2004. Soldier load carriage: historical, physiological, biomechanical, and medical aspects. Mil Med 169: 45-56.

Kokkinos, P., Sheriff, H., and Kheirbek, R. 2011. Physical inactivity and mortality risk. Cardiol Res Pract 2011: 924-945. 
Koskela, R.S. 1997. Mortality, morbidity and health selection among metal workers. Scand J Work Environ Health 23 Suppl 2: 1-80.

Kramer, M.K., Molenaar, D.M., Arena, V.C., Venditti, E.M., Meehan, R.J., Miller, R.G., Vanderwood, K.K., Eaglehouse, Y., and Kriska, A.M. 2015. Improving employee health: evaluation of a worksite lifestyle change program to decrease risk factors for diabetes and cardiovascular disease. J Occup Environ Med 57: 284-91.

Krause, N., Lynch, J., Kaplan, G.A., Cohen, R.D., Goldberg, D.E., and Salonen, J.T. 1997. Predictors of disability retirement. Scand J Work Environ Health 23: 403-13.

Kuehl, K.S., Kisbu-Sakarya, Y., Elliot, D.L., Moe, E.L., Defrancesco, C.A., Mackinnon, D.P., Lockhart, G., Goldberg, L., and Kuehl, H.E. 2012. Body mass index as a predictor of firefighter injury and workers' compensation claims. J Occup Environ Med 54: 579-82.

Kujala, V., Remes, J., Ek, E., Tammelin, T., and Laitinen, J. 2005. Classification of Work Ability Index among young employees. Occup Med Lond 55: 399-401.

Laflamme, L. and Menckel, E. 1995. Aging and occupational accidents: A review of the literature of the last three decades. Saf Sci 21: 145-161.

Larose, J., Boulay, P., Sigal, R.J., Wright, H.E., and Kenny, G.P. 2013. Age-related decrements in heat dissipation during physical activity occur as early as the age of 40. PLoS One 8: e83148.

Larose, J., Boulay, P., Wright-Beatty, H.E., Sigal, R.J., Hardcastle, S., and Kenny, G.P. 2014. Age-related differences in heat loss capacity occur under both dry and humid heat stress conditions. J Appl Physiol 1985 117: 69-79.

Leijten, F.R., van den Heuvel, S.G., Ybema, J.F., Robroek, S.J., and Burdorf, A. 2013. Do work factors modify the association between chronic health problems and sickness absence among older employees? Scand J Work Environ Health 39: 477-85.

Leijten, F.R., van den Heuvel, S.G., Ybema, J.F., van der Beek, A.J., Robroek, S.J., and Burdorf, A. 2014. The influence of chronic health problems on work ability and productivity at work: a longitudinal study among older employees. Scand J Work Environ Health 40: 473-82.

Lerner, D.J., Amick, B.C., 3rd, Malspeis, S., and Rogers, W.H. 2000. A national survey of health-related work limitations among employed persons in the United States. Disabil Rehabil 22: 225-32.

Leyk, D., Erley, O., Gorges, W., Ridder, D., Ruther, T., Wunderlich, M., Sievert, A., Essfeld, D., Piekarski, C., and Erren, T. 2009. Performance, training and lifestyle parameters of marathon runners aged 20-80 years: results of the PACE-study. Int J Sports Med 30: 360-5.

Leyk, D., Ruther, T., Wunderlich, M., Sievert, A., Essfeld, D., Witzki, A., Erley, O., Kuchmeister, G., Piekarski, C., and Lollgen, H. 2010. Physical performance in middle age and old age: good news for our sedentary and aging society. Dtsch Arztebl Int 107: 809-16. 
Li, C.Y. and Sung, F.C. 1999. A review of the healthy worker effect in occupational epidemiology. Occup Med Lond 49: 225-9.

Loeppke, R.R., Schill, A.L., Chosewood, L.C., Grosch, J.W., Allweiss, P., Burton, W.N., Barnes-Farrell, J.L., Goetzel, R.Z., Heinen, L., Hudson, T.W., Hymel, P., Merchant, J., Edington, D.W., Konicki, D.L., and Larson, P.W. 2013. Advancing workplace health protection and promotion for an aging workforce. J Occup Environ Med 55: 500-6.

Louhevaara, V. 1999. Is the physical work load equal for ageing and young blue-collar workers? Int J Ind Ergon 24: 559-564.

Lowery, J.T., Borgerding, J.A., Zhen, B., Glazner, J.E., Bondy, J., and Kreiss, K. 1998. Risk factors for injury among construction workers at Denver International Airport. Am J Ind Med 34: 113-20.

Lucas, R.A., Sarma, S., Schlader, Z.J., Pearson, J., and Crandall, C.G. 2015. Age-related changes to cardiac systolic and diastolic function during whole-body passive hyperthermia. Exp Physiol 100: 422-34.

Manini, T., Marko, M., VanArnam, T., Cook, S., Fernhall, B., Burke, J., and Ploutz-Snyder, L. 2007. Efficacy of resistance and task-specific exercise in older adults who modify tasks of everyday life. J Gerontol A Biol Sci Med Sci 62: 616-23.

Marks, B.L. 2002. Physiologic responses to exercise in older women. Top Geriatr Rehabil 18: 9-20.

Marques, N.R., Hallal, C.Z., Spinoso, D.H., Crozara, L.F., Morcelli, M.H., Karuka, A.H., Navega, M.T., and Goncalves, M. 2015. Age-related alterations in the activation of trunk and lower limb muscles during walking. J Back Musculoskelet Rehabil Sep 6. [Epub ahead of print], PMID: 26406207.

Martin, R.S., Farrah, J.P., and Chang, M.C. 2015. Effect of aging on cardiac function plus monitoring and support. Surg Clin North Am 95: 23-35.

McArdle, W.D., Katch, F.I., and Katch, V.L. 2001. Exercise Physiology. Energy, Nutrition, and Human Performance. USA: Lippincott Williams \& Wilkins.

McGill, S.M. 1997. The biomechanics of low back injury: implications on current practice in industry and the clinic. J Biomech 30: 465-75.

Meade, R.D., Lauzon, M., Poirier, M.P., Flouris, A.D., and Kenny, G.P. 2015. An evaluation of the physiological strain experienced by electrical utility workers in North America. J Occup Environ Hyg 12:708-20.

Miller, M.S., Bedrin, N.G., Callahan, D.M., Previs, M.J., Jennings, M.E., 2nd, Ades, P.A., Maughan, D.W., Palmer, B.M., and Toth, M.J. 2013. Age-related slowing of myosin actin crossbridge kinetics is sex specific and predicts decrements in whole skeletal muscle performance in humans. J Appl Physiol 1985 115: 1004-14. 
Miller, M.S., Callahan, D.M., and Toth, M.J. 2014. Skeletal muscle myofilament adaptations to aging, disease, and disuse and their effects on whole muscle performance in older adult humans. Front Physiol 5: 369.

Miranda, H., Gore, R.J., Boyer, J., Nobrega, S., and Punnett, L. 2015. Health Behaviors and Overweight in Nursing Home Employees: Contribution of Workplace Stressors and Implications for Worksite Health Promotion. Scientific World Journal 2015: 915359.

National Center for Health Statistics 2010. With Special Feature on Death and Dying. Hyattsville, MD: National Center for Health Statistics United States. Accessed from http://www.cdc.gov/nchs/data/hus/hus10.pdf. Accessed on March 5, 2015.

Nelson, M.D., Petersen, S.R., and Dlin, R.A. 2010. Effects of age and counseling on the cardiorespiratory response to graded exercise. Med Sci Sports Exerc 42: 255-64.

Ogden, C.L., Carroll, M.D., Kit, B.K., and Flegal, K.M. 2012. Prevalence of obesity and trends in body mass index among US children and adolescents, 1999-2010. JAMA 307: 483-90.

Ohta, M., Okufuji, T., Matsushima, Y., and Ikeda, M. 2004. The effect of lifestyle modification on physical fitness and work ability in different workstyles. J UOEH 26: 411-21.

Ostbye, T., Dement, J.M., and Krause, K.M. 2007. Obesity and workers' compensation: results from the Duke Health and Safety Surveillance System. Arch Intern Med 167: 766-73.

Ostchega, Y., Dillon, C.F., Lindle, R., Carroll, M., and Hurley, B.F. 2004. Isokinetic leg muscle strength in older americans and its relationship to a standardized walk test: data from the national health and nutrition examination survey 1999-2000. J Am Geriatr Soc 52: 977-82.

Oude Hengel, K.M., Blatter, B.M., Geuskens, G.A., Koppes, L.L., and Bongers, P.M. 2012. Factors associated with the ability and willingness to continue working until the age of 65 in construction workers. Int Arch Occup Environ Health 85: 783-90.

Parente, V., D'Antona, G., Adami, R., Miotti, D., Capodaglio, P., De Vito, G., and Bottinelli, R. 2008. Long-term resistance training improves force and unloaded shortening velocity of single muscle fibres of elderly women. Eur J Appl Physiol 104: 885-93.

Park, J. 2009. Obesity on the job. Available from: http://www.statcan.gc.ca/pub/75-001x/2009102/article/10789-eng.html: Statistics Canada.

Parkhouse, W. and Gall, B. 2004. Task frequency as a function of age for the powerline technician trade. Ergonomics 47: 660-70.

Paterson, D.H. and Warburton, D.E. 2010. Physical activity and functional limitations in older adults: a systematic review related to Canada's Physical Activity Guidelines. Int J Behav Nutr Phys Act 7: 38.

Payne, W. and Harvey, J. 2010. A framework for the design and development of physical employment tests and standards. Ergonomics 53: 858-71. 
Perera, S., Sardeshmukh, S.R., and Kulik, C.T. 2015. In or out: job exits of older workers. Asia Pacific J Hum Res 53: 4-21.

Pohjonen, T. 2001a. Age-related physical fitness and the predictive values of fitness tests for work ability in home care work. J Occup Environ Med 43: 723-30.

Pohjonen, T. 2001b. Perceived work ability of home care workers in relation to individual and work-related factors in different age groups. Occup Med Lond 51: 209-17.

Pratt, S.G. 2003. Work-Related Roadway Crashes - Challenges and Opportunities for Prevention. Cincinnati, OH: NIOSH.

Punakallio, A. 2003. Balance abilities of different-aged workers in physically demanding jobs. J Occup Rehabil 13: 33-43.

Punakallio, A., Lusa, S., and Luukkonen, R. 2003. Protective equipment affects balance abilities differently in younger and older firefighters. Aviat Space Environ Med 74: 1151-6.

Ramirez-Campillo, R., Castillo, A., de la Fuente, C.I., Campos-Jara, C., Andrade, D.C., Alvarez, C., Martinez, C., Castro-Sepulveda, M., Pereira, A., Marques, M.C., andIzquierdo, M. 2014. High-speed resistance training is more effective than low-speed resistance training to increase functional capacity and muscle performance in older women. Exp Gerontol 58: 51-7.

Ramly, E., Kaafarani, H.M., and Velmahos, G.C. 2015. The effect of aging on pulmonary function: implications for monitoring and support of the surgical and trauma patient. Surg Clin North Am 95: 53-69.

Reilly, T. and Tipton, M. 2005. Task-based standards for lifeboat crew: Avoiding ageism. International Congress Series 1280: 219-223.

Ritvanen, T., Louhevaara, V., Helin, P., Halonen, T., and Hanninen, O. 2007. Effect of aerobic fitness on the physiological stress responses at work. Int J Occup Med Environ Health 20: 1-8.

Robroek, S.J., Schuring, M., Croezen, S., Stattin, M., and Burdorf, A. 2013. Poor health, unhealthy behaviors, and unfavorable work characteristics influence pathways of exit from paid employment among older workers in Europe: a four year follow-up study. Scand J Work Environ Health 39: 125-33.

Rogers, E. and Wiatrowski, W. 2005. Injuries, illnesses, and fatalities among older workers. Mon Labor Rev 128: 24-30.

Rose, M.R. 1991. Evolutionary Biology of Aging. New York: Oxford University Press.

Savinainen, M., Nygard, C.H., and Ilmarinen, J. 2004a. A 16-year follow-up study of physical capacity in relation to perceived workload among ageing employees. Ergonomics 47: 1087-102.

Savinainen, M., Nygard, C.H., Korhonen, O., and Ilmarinen, J. 2004b. Changes in physical capacity among middle-aged municipal employees over 16 years. Exp Aging Res 30: 1-22. 
Schaap, L.A., Koster, A., and Visser, M. 2013. Adiposity, muscle mass, and muscle strength in relation to functional decline in older persons. Epidemiol Rev 35: 51-65.

Schibye, B., Hansen, A.F., Sogaard, K., and Christensen, H. 2001. Aerobic power and muscle strength among young and elderly workers with and without physically demanding work tasks. Appl Ergon 32: 425-31.

Schrage, W.G., Eisenach, J.H., andJoyner, M.J. 2007. Ageing reduces nitric-oxide- and prostaglandin-mediated vasodilatation in exercising humans. J Physiol 579: 227-36.

Schwatka, N.V., Butler, L.M., andRosecrance, J.R. 2012. An aging workforce and injury in the construction industry. Epidemiol Rev 34: 156-67.

Sehl, M.E. and Yates, F.E. 2001. Kinetics of human aging: I. Rates of senescence between ages 30 and 70 years in healthy people. J Gerontology Biol Sci Med Sci 56: B198-B208.

Seitsamo, J., Tuomi, K., and Martikainen, R. 2007. Activity, functional capacity and well-being in ageing Finnish workers. Occup Med Lond 57: 85-91.

Shishlov, K.S., Schoenfisch, A.L., Myers, D.J., and Lipscomb, H.J. 2011. Non-fatal construction industry fall-related injuries treated in US emergency departments, 1998-2005. Am J Ind Med 54: $128-35$.

Silverstein, M. 2008. Meeting the challenges of an aging workforce. Am J Ind Med 51: 269-80.

Sluiter, J.K. 2006. High-demand jobs: age-related diversity in work ability? Appl Ergon 37: 429-40.

Sluiter, J.K. and Frings-Dresen, M.H. 2007. What do we know about ageing at work? Evidencebased fitness for duty and health in fire fighters. Ergonomics 50: 1897-913.

Soer, R., Brouwer, S., Geertzen, J.H., van der Schans, C.P., Groothoff, J.W., and Reneman, M.F. 2012. Decline of functional capacity in healthy aging workers. Arch Phys Med Rehabil 93: 2326-32.

Spirduso, W.W. 2005. Physical dimensions of aging. Champaign, IL: Human Kinetics.

Stapleton, J.M., Poirier, M.P., Flouris, A.D., Boulay, P., Sigal, R.J., Malcolm, J., and Kenny, G.P. 2015a. Aging impairs heat loss, but when does it matter? J Appl Physiol 1985 118: 299309.

Stapleton, J.M., Poirier, M.P., Flouris, A.D., Boulay, P., Sigal, R.J., Malcolm, J., and Kenny, G.P. 2015b. At what level of heat load are age-related impairments in the ability to dissipate heat evident in females? PLoS One 10: e0119079.

Statistics Canada 2011. Portrait of Canada's Labour Force: Government of Canada. 
Strating, M., Bakker, R.H., Dijkstra, G.J., Lemmink, K.A., and Groothoff, J.W. 2010. A jobrelated fitness test for the Dutch police. Occup Med Lond 60: 255-60.

Taylor, N.A. and Groeller, H. 2003. Work-based physiological assessment of physicallydemanding trades: a methodological overview. J Physiol Anthropol Appl Human Sci 22: 7381 .

Tipton, M.J., Milligan, G.S., and Reilly, T.J. 2013. Physiological employment standards I. Occupational fitness standards: objectively subjective? Eur J Appl Physiol 113: 2435-46.

Tishman, F.M., Van Looy, S., and Bruyere, S.M. 2012. Employer strategies for responding to an aging workforce. Rutgers: State University of New Jersey.

Toth, M.J., Miller, M.S., VanBuren, P., Bedrin, N.G., LeWinter, M.M., Ades, P.A., and Palmer, B.M. 2012. Resistance training alters skeletal muscle structure and function in human heart failure: effects at the tissue, cellular and molecular levels. J Physiol 590: 1243-59.

Tseng, L.A., Delmonico, M.J., Visser, M., Boudreau, R.M., Goodpaster, B.H., Schwartz, A.V., Simonsick, E.M., Satterfield, S., Harris, T., and Newman, A.B. 2014. Body composition explains sex differential in physical performance among older adults. J Gerontol A Biol Sci Med Sci 69: 93-100.

Tunceli, K., Li, K., and Williams, L.K. 2006. Long-term effects of obesity on employment and work limitations among U.S. Adults, 1986 to 1999. Obesity Silver Spring 14: 1637-46.

Tuomi, K., Huuhtanen, P., Nykyri, E., and Ilmarinen, J. 2001. Promotion of work ability, the quality of work and retirement. Occup Med Lond 51: 318-24.

Tuomi, K., Ilmarinen, J., Eskelinen, L., Jarvinen, E., Toikkanen, J., and Klockars, M. 1991. Prevalence and incidence rates of diseases and work ability in different work categories of municipal occupations. Scand J Work Environ Health 17 Suppl 1: 67-74.

van de Vijfeijke, H.M., Leijten, F.R.M.M., yBEMA, J.F.P., van der Beek, A.J., Burdorf, A., and Taris, T.W. 2013. Differential effects of mental and physical health and coping style on work ability: A 1-year follow-up study among aging workers. J Occup Environ Hyg 55: 1238-43.

van den Berg, T.I.J., Elders, L.A., de Zwart, B.C., and Burdorf, A. 2009. The effects of workrelated and individual factors on the Work Ability Index: a systematic review. Occup Environ Med 66: 211-220.

Vaz Fragoso, C.A. and Gill, T.M. 2012. Respiratory impairment and the aging lung: a novel paradigm for assessing pulmonary function. J Gerontol A Biol Sci Med Sci 67: 264-75.

Viester, L., Verhagen, E.A., Bongers, P.M., and van der Beek, A.J. 2015. The effect of a health promotion intervention for construction workers on work-related outcomes: results from a randomized controlled trial. Int Arch Occup Environ Health 88:789-98. 
Vilela, B.L., Benedito Silva, A.A., de Lira, C.A., and Andrade Mdos, S. 2015. Workplace exercise and educational program for improving fitness outcomes related to health in workers: a randomized controlled trial. J Occup Environ Med 57: 235-40.

Vincent, H.K., Vincent, K.R., and Lamb, K.M. 2010. Obesity and mobility disability in the older adult. Obes Rev 11: 568-79.

von Bonsdorff, M.B., Seitsamo, J., Ilmarinen, J., Nygard, C.H., von Bonsdorff, M.E., and Rantanen, T. 2011a. Work ability in midlife as a predictor of mortality and disability in later life: a 28-year prospective follow-up study. CMAJ 183: E235-42.

von Bonsdorff, M.E., Kokko, K., Seitsamo, J., von Bonsdorff, M.B., Nygard, C.H., Ilmarinen, J., and Rantanen, T. 2011b. Work strain in midlife and 28-year work ability trajectories. Scand J Work Environ Health 37: 455-63.

Walker, A., Driller, M., Argus, C., Cooke, J., and Rattray, B. 2014. The ageing Australian firefighter: an argument for age-based recruitment and fitness standards for urban fire services. Ergonomics 57: 612-21.

Westerholm, P. and Kilbom, A. 1997. Aging and work: the occupational health services' perspective. Occup Environ Med 54: 777-80.

Wilcosky, T. and Wing, S. 1987. The healthy worker effect. Selection of workers and work forces. Scand J Work Environ Health 13: 70-2.

Wind, H., Gouttebarge, V., Kuijer, P.P., Sluiter, J.K., and Frings-Dresen, M.H. 2009. Effect of Functional Capacity Evaluation information on the judgment of physicians about physical work ability in the context of disability claims. Int Arch Occup Environ Health 82: 1087-96.

Yeh, T.T., Cinelli, M.E., Lyons, J.L., and Lee, T.D. 2015. Age-related changes in postural control to the demands of a precision task. Hum Mov Sci 44: 134-42.

Yoo, W.G., Park, S.Y., and Lee, M.R. 2011. Relationship between active cervical range of motion and flexion-relaxation ratio in asymptomatic computer workers. J Physiol Anthropol 30: 203-7.

Zavanela, P.M., Crewther, B.T., Lodo, L., Florindo, A.A., Miyabara, E.H., and Aoki, M.S. 2012. Health and fitness benefits of a resistance training intervention performed in the workplace. $\mathbf{J}$ Strength Cond Res 26: 811-7. 


\section{Figure Legends}

Figure 1. Complex age-related physiological adjustments leading towards a decrease in work performance.

Figure 2. Recommendations for the management of shift workers over the age of 50 years.

Figure 3. Strategies to accommodate workers and facilitate optimization of work ability and productivity. 


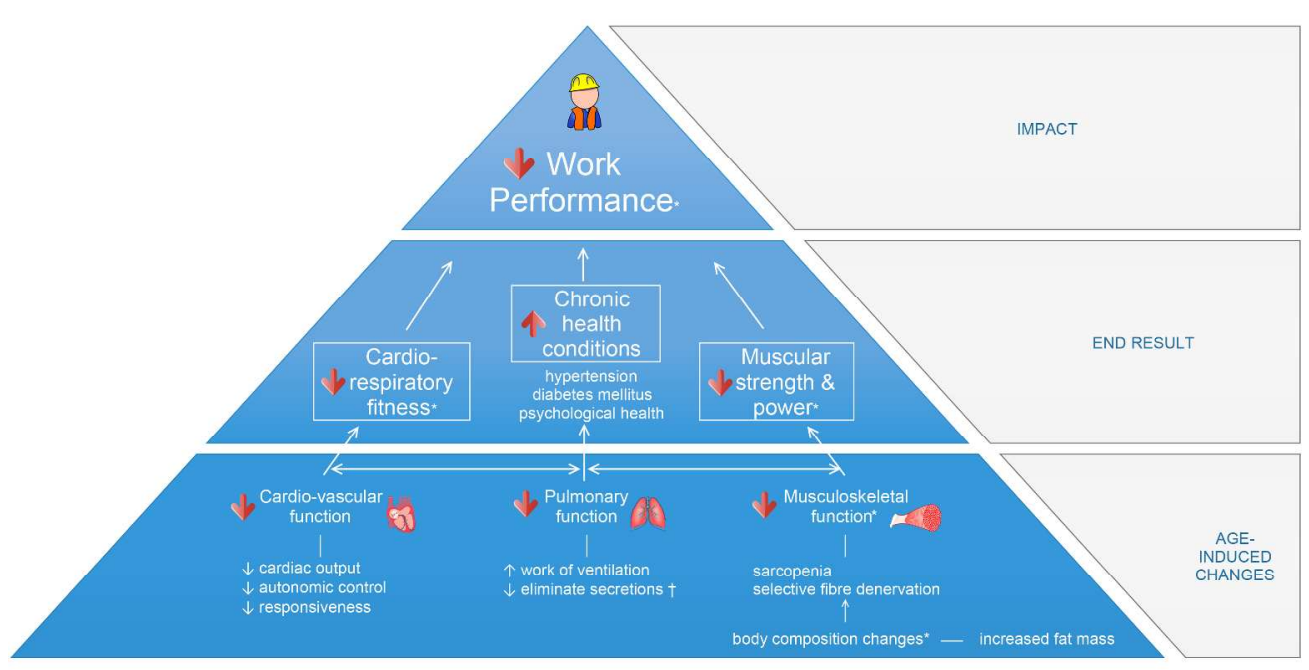

* confirmed or suspected role for sex-related differences in aging

$296 \times 158 \mathrm{~mm}(300 \times 300 \mathrm{DPI})$ 


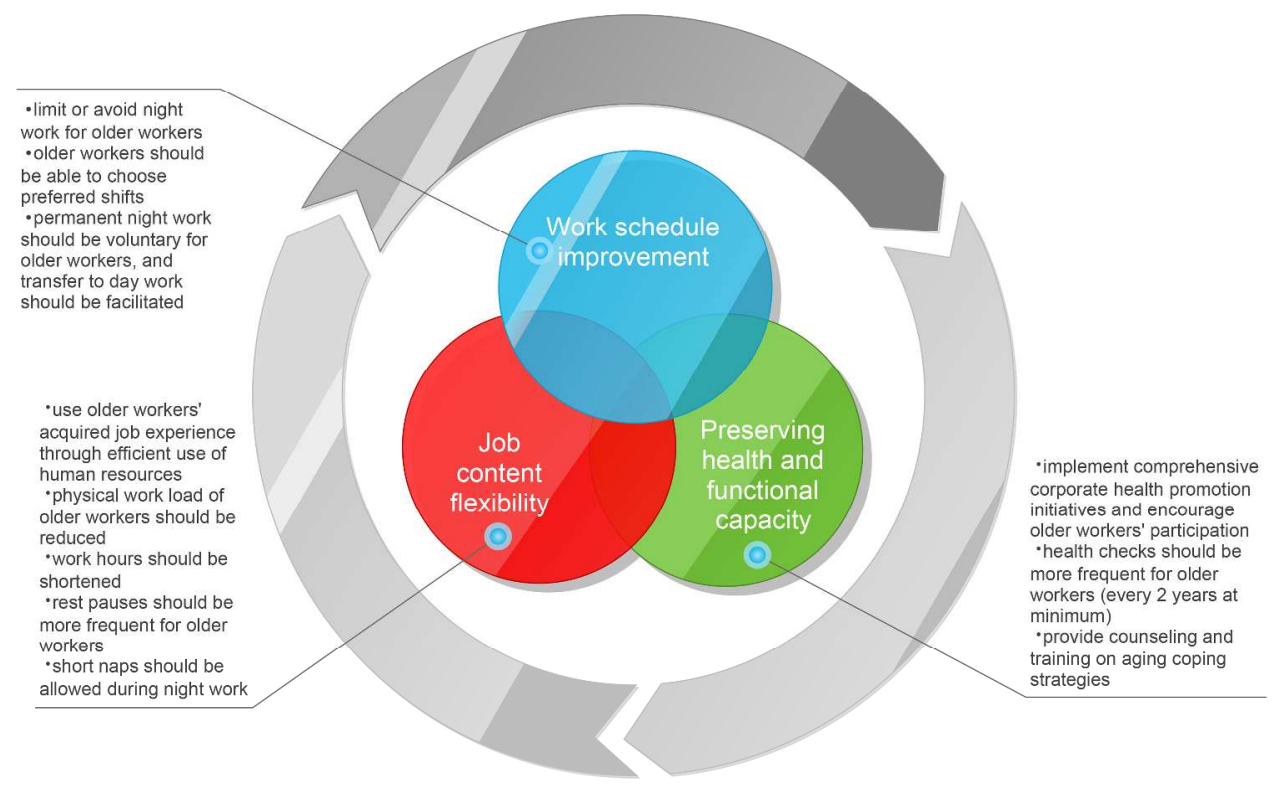

$281 \times 180 \mathrm{~mm}(300 \times 300 \mathrm{DPI})$ 

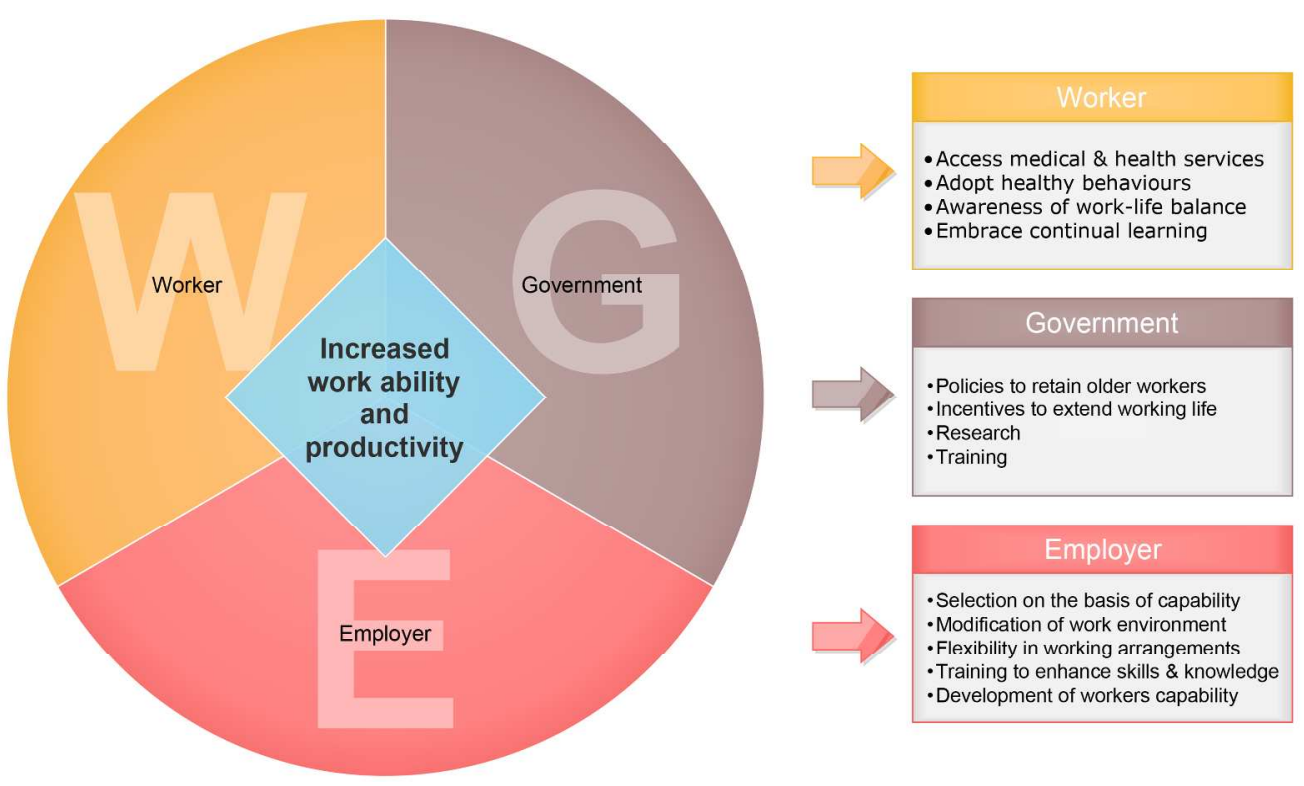

$230 \times 135 \mathrm{~mm}(300 \times 300 \mathrm{DPI})$ 